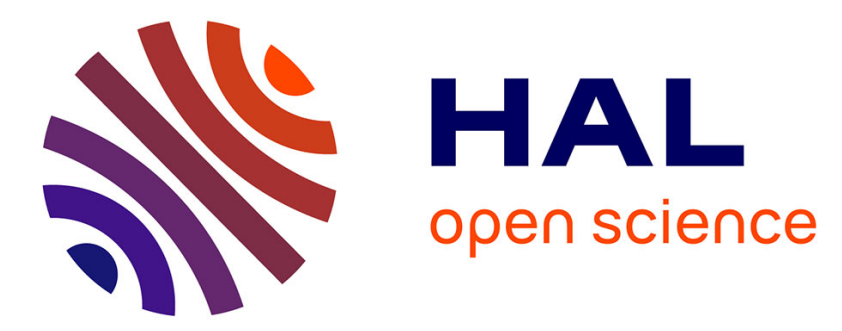

\title{
On the CO2 emissions determinants during the EU ETS Phases I and II : a plant-level analysis merging the EUTL and Platts power data
}

\author{
Benoit Chèze, Julien Chevallier, Nicolas Berghmans, Emilie Alberola
}

\section{- To cite this version:}

Benoit Chèze, Julien Chevallier, Nicolas Berghmans, Emilie Alberola. On the CO2 emissions determinants during the EU ETS Phases I and II : a plant-level analysis merging the EUTL and Platts power data: Cahiers de l'Economie, Série Recherche, $n^{\circ}$ 125. 2019. hal-03190419

\section{HAL Id: hal-03190419 \\ https://hal-ifp.archives-ouvertes.fr/hal-03190419}

Preprint submitted on 6 Apr 2021

HAL is a multi-disciplinary open access archive for the deposit and dissemination of scientific research documents, whether they are published or not. The documents may come from teaching and research institutions in France or abroad, or from public or private research centers.
L'archive ouverte pluridisciplinaire HAL, est destinée au dépôt et à la diffusion de documents scientifiques de niveau recherche, publiés ou non, émanant des établissements d'enseignement et de recherche français ou étrangers, des laboratoires publics ou privés. 


\section{LES CAHIERS DE L'ÉCONOMIE}

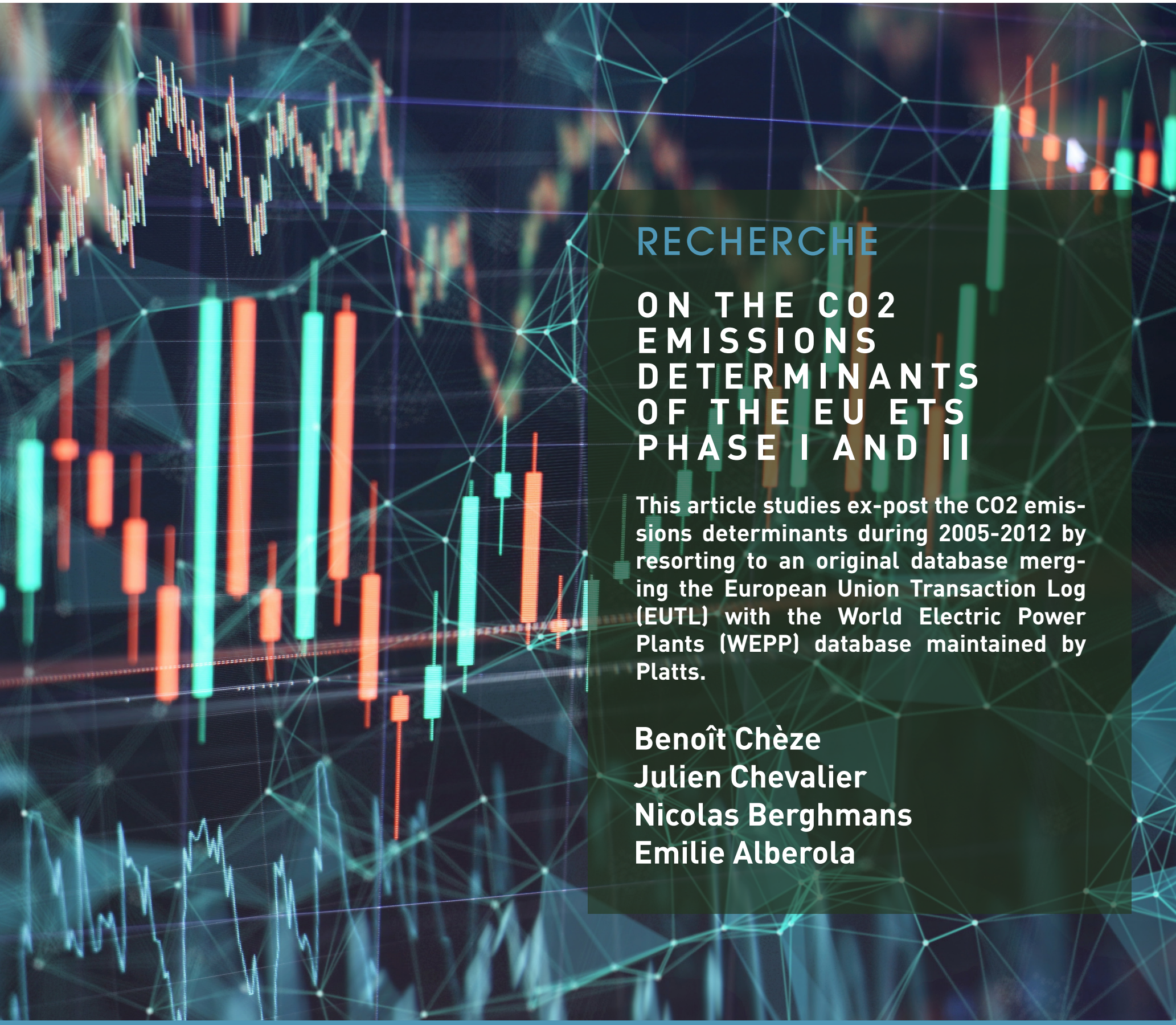


La collection "Les Cahiers de l'Économie" a pour objectif de présenter les travaux réalisés à IFP Energies nouvelles et IFP School qui traitent d'économie, de finance ou de gestion de la transition énergétique. La forme et le fond peuvent encore être provisoires, notamment pour susciter des échanges de points de vue sur les sujets abordés. Les opinions exprimées dans cette collection appartiennent à leurs auteurs et ne reflètent pas nécessairement le point de vue d'IFP Energies nouvelles ou d'IFP School. Ni ces institutions ni les auteurs n'acceptent une quelconque responsabilité pour les pertes ou dommages éventuellement subis suite à l'utilisation ou à la confiance accordée au contenu de ces publications.

Pour toute information sur le contenu, contacter directement l'auteur.

The collection "Les Cahiers de l'Économie" aims to present work carried out at IFP Energies nouvelles and IFP School dealing with economics, finance or energy transition management. The form and content may still be provisional, in particular to encourage an exchange of views on the subjects covered. The opinions expressed in this collection are those of the authors and do not necessarily reflect the views of IFP Energies nouvelles or IFP School. Neither these institutions nor the authors accept any liability for loss or damage incurred as a result of the use of or reliance on the content of these publications.

For any information on the content, please contact the author directly.

\title{
Pour toute information complémentaire For any additional information
}

\author{
Victor Court \\ IFP School \\ Centre Economie et Management de l'Energie \\ Energy Economics and Management Center \\ victor.court@ifpen.fr \\ Tél +33147527317
}




\title{
On the $\mathrm{CO}_{2}$ emissions determinants during the EU ETS Phases I and II: a plant-level analysis merging the EUTL and Platts power data
}

\author{
Benoît Chèze ${ }^{\mathrm{a}, \mathrm{b}}$, Julien Chevallier ${ }^{\mathrm{c}^{*}}$, Nicolas Berghmans ${ }^{\mathrm{d}}$, and Emilie Alberola ${ }^{\mathrm{e}}$ \\ ${ }^{\text {a }}$ IFP Energies nouvelles, 1-4 avenue de Bois-Préau, 92852 Rueil-Malmaison, France. \\ b EconomiX-CNRS, Université Paris-Nanterre ; UMR210 Economie Publique, INRA, Climate \\ Economics Chair, Paris, France \\ ${ }^{\mathrm{c}}$ Université Paris 8 (LED), 2 avenue de la Liberté, 93526 Saint-Denis, France. \\ ${ }^{\mathrm{d}}$ IDDRI, Paris, France. \\ ${ }^{\mathrm{e}}$ EcoAct, Climate Policy \& Market Mechanisms, Paris.
}

Revised February 2019

\begin{abstract}
:
This article studies ex-post the $\mathrm{CO}_{2}$ emissions determinants during 2005-2012 by resorting to an original database merging the European Union Transaction Log (EUTL) with the World Electric Power Plants (WEPP) database maintained by Platts. We estimate the main drivers of $\mathrm{CO}_{2}$ emissions for the 1,453 power plants included in the EU ETS using plant-level panel data. During phases I and II, there has been a debate about whether the economic crisis was ultimately the only factor behind the fall in $\mathrm{CO}_{2}$ emissions. We find that the EU ETS kept some degree of effectiveness but only during phase I (2005-07). During phase II (2008-12), its impact has been largely impeded by the deep economic recession in 2008-2009 which became the leading cause of the emissions reduction. We disentangle the analysis not only by periods but also for each type of power plants. We conclude that the EU Commission's flagship climate policy could and should be enhanced by better coordination of overlapping climate policies.
\end{abstract}

JEL Codes: C23; L94; Q54.

Keywords: European carbon price; Plant-level analysis; Dynamic Panel data; EUTL; Platts.

Acknowledgments: For helpful comments and suggestions on previous drafts of this paper, the authors wish to thank Ross McKitrick, Ian Dickie, John Holding, Radoslaw Stefanski, Stéphanie Monjon, Anna Créti, Bertrand Villeneuve, as well as participants at Envecon 2014: Applied Environmental Economics Conference (Royal Economic Society, London, UK), the 37th International Conference of the International Association for Energy Economics (IAEE, New York, USA), the World Congress of Environmental and Resource Economists (WCERE 2014, Istanbul, Turkey), the $21^{\text {st }}$ Annual Conference of the European Association of Environmental and Resource Economists (EAERE 2015, University of Helsinki, Finland), the French Association of Environmental \& Resource Economists (FAERE 2016) Thematic Meeting, and the 23rd EAERE annual conference (2017), Athens University of Economics and Business, Greece and the LEDa Economics Seminar (University Paris Dauphine 2019). The authors also gratefully acknowledge financial support from the CDC Climat Research and IFPEN institutes for providing database access.

*Corresponding author at Julien.chevallier04@univ-paris8.fr 


\section{Introduction}

Has the European Union Emissions Trading Scheme (EU ETS) effectively reduced $\mathrm{CO}_{2}$ emissions? At the current price of 22.82 Euro per ton of $\mathrm{CO}_{2}$ for futures traded on the ICE ECX, the aim of this scheme, which was set up in 2005, is to reduce $\mathrm{CO}_{2}$ emissions in Europe by setting emissions caps for over 11,700 installations $^{1}$ which are required to return a volume of allowances that corresponds to their verified $\mathrm{CO}_{2}$ emissions for each annual compliance assessment. The EU ETS is in force in 31 countries $^{2}$ and covers over $45 \%$ of their overall greenhouse gas (GHG) emissions. Phase II lasted from 2008 to 2012. This article aims at studying the determinants of the $\mathrm{CO}_{2}$ emissions during 2005-2012 (first and second phases) of the power plants regulated by the EU ETS. Although Phase III of the EUETS has been practiced for several years until 2020, this article focuses exclusively on ex-post econometric analysis, hence on Phases I-II only that have been completed.

The European Commission stated in its report on the operation of the EU ETS in November 2012 that "the EU ETS is facing a challenge in the form of an increasing allowance surplus, primarily because the economic downturn has reduced emissions by more than was expected." 3 It is indeed likely that the slowdown in economic activity within the European Union did have an impact on the fall in $\mathrm{CO}_{2}$ emissions, but can we argue that the downturn was the main reason or even the only reason for that fall?

Economists typically weigh several criteria for gauging the performance of an emissions trading system. Around the notion of economic efficiency, environmental effectiveness refers to the reduction of emissions that is attributable to the instrument, whereas cost-effectiveness refers to the marginal abatement cost curve. Regarding transaction costs, public finance and administrative issues are largely ignored in empirical applications.

Besides the 2008 economic recession, the environmental effectiveness of the EU ETS may be endangered by overlapping climate policies. We distinguish two kinds of overlaps. On the one hand, several environmental regulation tools coexist with emissions trading: i) the EU Commission ClimateEnergy Package, ii) renewable energy deployment objectives and iii) specific sectors regulations. On the other hand, this policy mix is implemented at both the regional and national levels.

\footnotetext{
${ }^{1}$ The sectors covered are mainly: energy production (which accounts for over $60 \%$ of the total emissions concerned by the EU ETS), and the "other combustion" segment, which includes units that are typically used to generate heat in order to support other industrial or urban activities, followed by cement plants, refineries and steel works, which account for roughly the same level of emissions.

${ }^{2}$ The 27 Member States, Croatia, Norway, Liechtenstein, and Iceland.

${ }^{3}$ European Commission, Climate Action, http://ec,europa,eu/clima/policies/ets/index_en,htm
} 
Indeed, factors other than the economic crisis could also have played a role, especially the actual efforts made to decarbonize the economy, and increasing renewable energy's share in the energy mix. Indeed, the commitments made at the European level, which resulted in the so-called "20-20-20" targets ${ }^{4}$, were implemented via a series of directives, including the directives on renewable energy and energy efficiency, which were combined with national policies. These commitments were reflected by notable development of renewable energy in most States. ${ }^{5}$ In which case, can we estimate to what extent these efforts contributed to reducing $\mathrm{CO}_{2}$ emissions? Likewise, we need to ask whether changes in the price of energy affected $\mathrm{CO}_{2}$ emissions or whether the allowance system and specifically the carbon "price signal" that it reflects, effectively played a role by encouraging fuel-switching in energies and investments in technologies that emit less carbon.

The power sector is also exposed to different kinds of energy or environmental policies that also impact fossil fuel power plant emissions levels. On top of the carbon price that was established in 2005, national policies to develop renewable energy are widespread in the European Union. Since 2009, national targets are consolidated in a directive at the European level, and the Member States established action plans to reach the desired development in renewable energy ${ }^{6}$. According to them, electricity from renewable sources will reach $33 \%$ of the total final electricity consumption at the European level in 2020, when it was only $15 \%$ in 2005. To reach their objectives, many Member States have put in place deployment policies such as feed-in tariffs or "green" certificates (Ringel, 2006) that were successful in channeling investments in renewable energy production without any connection to the $\mathrm{CO}_{2}$ price level. Other environmental command and control policies are also applied in the European power sector, like the Large Combustion Plant Directive (LCPD) that limits the use of some power plants since 2008. We thus can take advantage of the data provided in the EU Transaction Log on power plants participating in the EU ETS, to evaluate the impact regarding $\mathrm{CO}_{2}$ emissions of the carbon price, but other complementary policies that affect emissions levels.

We choose to focus our analysis on the power sector for various reasons. It is the largest sector in the EU ETS regarding $\mathrm{CO}_{2}$ emissions. Half of the allowances were allocated to power or Combined Heat and Power (CHP) plants (see Figure 5 in the Appendix). It differentiated from the other sectors also because, since 2005, it is the only industry that as a whole was short in European Union Allowances (EUAs), i.e., its free allocation of EU allowances was lower than the amount of $\mathrm{CO}_{2}$ it emitted. This has been anticipated by the Member States. It can be explained by the perception that cheaper

\footnotetext{
${ }^{4}$ Directive 2009/28/EC on renewable energies established a European framework for the promotion of renewable energies, which set binding national renewable energy targets, in order to achieve a $20 \%$ share of renewable energy in energy endconsumption by 2020 , to reduce $\mathrm{CO}_{2}$ emissions in European Union countries, and to increase energy efficiency by $20 \%$ by 2020.

${ }^{5}$ European Commission, Renewable Energy Progress Report, 2013, page 3. http://eur-lex,europa,eu/LexUriServ/LexUriServ,do?uri=COM:2013:0175:FIN:FR:HTML

${ }^{6}$ All national action plans on renewable energy are freely available on the European Commission website: http://ec.europa.eu/energy/renewables/action_plan_en.htm
} 
abatement options exist in the power sector than in other industrial sectors, and the low risk of carbon leakage in power production (Ellerman and Buchner, 2008; Monjon and Quirion, 2011). It has led power producers to include the carbon price in their operating decisions.

Technical power plants' characteristics but also economic and energy market conditions should influence the $\mathrm{CO}_{2}$ emissions of power plants. However, the magnitude of the influence of these $\mathrm{CO}_{2}$ emissions determinants also seems to depend on the power plant under consideration, which varies widely among the EU ETS. To take into account the heterogeneity of installations, the role played by these variables on the $\mathrm{CO}_{2}$ emissions of power plants concerned by the EU ETS is estimated using panel-data econometrics. The focus of this article is to provide quantitative answers to these questions, based on panel data econometrics for the EU 27. Based on an original merging methodology of the EUTL and Platts power data, we attempt to link $\mathrm{CO}_{2}$ emissions with a series of explanatory variables that have an impact on emission trends and to gauge their relative contributions. Cross-sectional units of the panel-data sample correspond to the 1,453 electricity generation plants running on fossil fuels in Europe. We study the different factors reducing $\mathrm{CO}_{2}$ emissions and evaluate the relative contribution of the EU ETS (carbon price), renewable energy deployment, command \& control directives on local pollutants, and the economic crisis on the abatement in the European power sector.

The gist of the results may be summarized as follows. Dynamic panel data regressions investigate the driving factors of $\mathrm{CO}_{2}$ emission reductions of power plants regulated under the EU ETS. From the list of potential explanatory variables - including economic activity, energy prices, power plant technology, and climate \& energy policies - the 2008/09 recession stands out as the primary driver of emission reductions. In contrast, the EU ETS carbon price appears to have no consistent effect. Based on these findings, we may cautiously suggest that the EU ETS has been inefficient regarding inducing emission reductions in the period 2008-2012.

The remainder of the paper is organized as follows. Section 2 presents the literature review. Section 3 details the methodology. Section 4 contains the empirical results and policy implications. Section 5 concludes.

\section{Background}

Perhaps among the first in this strand of literature, Ellerman and Buchner $(2007,2008)$ make use of preliminary verified emissions and allowance allocation data to diagnose the extent of "overallocation" during the 2005-06 period. Such an early empirical evaluation of the explanatory factors of $\mathrm{CO}_{2}$ emissions in the power sector has become a highly cited paper in the environmental economics 
literature (totaling more than 1,000 citations and counting at the time of writing) in its two versions published in Environmental \& Resource Economics and the Review of Environmental Economics \& Policy.

Anderson and Di Maria (2011) provide another ex-post evaluation of phase I by resorting to dynamic panel data modeling. Based on emissions data from the Community Independent Transactions Log (CITL) and Industrial $\mathrm{CO}_{2}$ emissions from Eurostat (at the aggregated country level), their analysis hardly establishes that abatement occurred over 2005-2007. This view is shared by most studies which reflect on this trial period of the EU ETS, gearing towards the conclusion that no abatement would be indicated (Convery and Redmond, 2007). Martin et al. (2016) have further extended this argument to 2008-2012; based on a literature review on aggregated industrial data, the evidence of the effect of the EU ETS on emissions of participating firms is not conclusive.

Plant-level data would provide more insights into the emissions reductions achieved under the EU ETS. Abrell et al. (2011) perform such a task using robust regression, merging CITL and Amadeus data to determine plant-level performance. Overall, they capture $59 \%$ of the total verified emissions between 2005 and 2008. After controlling for various characteristics of firms' performance, their results imply some degree of emissions abatement during phase II. This somewhat indirect finding stems from the fact that emissions reductions were not only achieved by reductions in the economic activity of the firms during the sample period. The authors admit, however, a few caveats in their data treatment procedure, and conclude that their results should be interpreted with caution.

Additional works exist based on plant-level data. Zaklan (2013) also resorts to CITL and Amadeus matched data to establish plant-level evidence of inter- and intra-firm transfers of permits during 20052007. Jaraite and Kazukauskas (2012) perform a similar analysis based on transactions between EU ETS installations. Bushnell et al. (2013) investigate the effect of the EU ETS on firm profits by using CITL, Orbis and exchange data. Further on this topic, Jong et al. (2014) match CITL and Orbis data to measure the impact of allowance over-allocation on firms' share prices, especially around the April 2006 market crash. Martin et al. (2014) match CITL and Orbis data as well to study industry relocation during the first years of the EU ETS. Petrick and Wagner (2014) study the causal impact of the EU ETS on manufacturing firms in Germany and suggest that the policy caused treated firms to abate one-fifth of their $\mathrm{CO}_{2}$ emissions between 2007 and 2010 (relative to non-treated firms). Wagner et al. (2014) find that ETS-regulated manufacturing plants in France reduced emissions by an average of $15-20 \%$, with most reduction occurring in 2008.

Another study, in particular, has sought to evaluate directly emissions abatement achieved within the EU ETS Phases I and II. Jaraite and Di Maria (2016) survey Lithuanian firms between 2003 and 2010, 
and conclude that ETS participation did not lead to a reduction in $\mathrm{CO}_{2}$ emissions. Compared to this work, our article features complete ex-post (2008-12) plant-level analysis of the power sector at the level of the EU 27, by merging for the first time the EUTL and Platts data.

In parallel, another strand of literature has developed on the optimal policy mix to reduce $\mathrm{CO}_{2}$ emissions in the power sector. According to Fischer and Newell (2004), technology policies should remain confined to the promotion of research and development, thus rejecting promotion policies by early market deployment. De Jonghe et al. (2009) and Böhringer et al. (2008) show the interdependence of renewable policies and carbon pricing, which leads to the inefficiency of one of them if they are poorly calibrated. Fisher and Peronas (2010) argue that in the presence of efficient carbon pricing, other policies such as renewable energy support offer no additional environmental benefits, and have to be justified by other market failures. In the presence of uncertainty on the environmental benefits of the future policy, renewable energy subsidies can be justified only by their contribution to the mitigation of $\mathrm{CO}_{2}$ emissions (Hoel, 2012; Lecuyer and Quirion, 2013; Antimiani et al., 2016).

As for the assessment of $\mathrm{CO}_{2}$ abatement coming from renewable energy development, Weigt et al. (2013) examine the impact of the development of renewable energy in Germany on demand for carbon allowances (and therefore on $\mathrm{CO}_{2}$ emissions). Approximately 10-16\% of the fall in $\mathrm{CO}_{2}$ emissions in the electricity sector between 2005 and 2011 can be explained by the increase in renewable energy's share of the energy mix.

The academic literature today provides no empirical evaluation of the explanatory factors of $\mathrm{CO}_{2}$ emissions in the power sector over the period 2005-2012. Nevertheless, some studies attempt to evaluate the emissions reductions achieved by the implementation of the EU ETS during the first phase. Ellerman and Buchner (2008) find a reduction in $\mathrm{CO}_{2}$ emissions between 50 and $100 \mathrm{Mt}$ over 2005-2007. Delarue et al. (2008) evaluate emissions reductions that were between 34 and $88 \mathrm{Mt}$ in 2005, between 19 and 59 Mt in 2006. Feilhauer and Ellerman (2008) estimate that reductions range between 13 and $122 \mathrm{Mt}$. 


\section{Methodology}

This section informs us about the database merging procedure, before moving to the exposition of the explanatory variables of $\mathrm{CO}_{2}$ emissions. Note that the exhaustive list of explanatory variables can be found in Table 5 of the Appendix. The panel data modeling is also outlined.

\subsection{Merging of databases}

All industrial sites participating in the EU ETS (approx. 12,000 sites in 31 countries) are required to report their $\mathrm{CO}_{2}$ emissions every year. We have identified the power plants by merging two databases:

- The European Union Transaction $\log (E U T L)^{7}$ available on the website of the European Commission, with

- The World Electric Power Plants (WEPP) database maintained by Platts ${ }^{8}$.

The Appendix contains detailed information on the merging procedure. This methodology allows identifying 1,453 accounts in the EUTL between 2005 and 2012 that correspond to power/CHP plants. To write this paper, we need both data on verified emissions (EUTL) and technical characteristics of the power plants (Platts). The originality in merging these two datasets stems from the fact that - to our best knowledge - this is the first empirical study dedicated to the EU ETS that performs such a task in scholarly writing.

Among these 1,453 power plants, 1,141 were active from 2005 to 2012, 68 retired between 2005 and 2012, and 244 appeared after 2005 either because they were new entrants or because their country integrated the EU ETS. For example, 53 came from the integration of Bulgaria and Romania in the EU ETS in 2007 and Norway in 2008. We include in the sample all these power plants for each year they were in service, i.e., they reported verified emissions. ${ }^{9}$

As a whole, the power and CHP power plants saw a decrease in their $\mathrm{CO}_{2}$ emissions by $186 \mathrm{Mt}$ during phase 2 (2008-2012), equal to a $14.2 \%$ fall from 1,306 Mt in 2007 - the last year of phase 1 - to 1,120 million tonnes (Mt) in 2012. The fall in $\mathrm{CO}_{2}$ emissions in the power industry would, therefore, appear to be more circumstantial than structural. Trends in $\mathrm{CO}_{2}$ emissions were different according to the primary fuel used by the power plant.

\footnotetext{
7 Formerly known as the Community Independent Transaction Log (CITL), available at: http://ec.europa.eu/environment/ets/

${ }^{8}$ http://www.platts.com/products/world-electric-power-plants-database

9 Excluding Bulgaria and Romania, as their inclusion in the EU ETS became effective in 2007, the date when they joined the EU.
} 
After declining sharply in 2008 and 2009, primarily due to the economic downturn, $\mathrm{CO}_{2}$ emissions from coal-fired power plants increased between 2009 and 2012, reaching $846 \mathrm{MtCO}_{2}$ in 2012. This increase is partly explained by a rebound in coal's competitiveness as a fuel for thermal power plants in Europe, mainly due to the export of the excess coal produced in the United States to Europe, and to the collapse in the carbon price in Europe, which no longer penalized coal-fired power plants in 2011 and 2012.

As displayed in Figure 1, gas and oil-fired power plants experienced the sharpest decline in their $\mathrm{CO}_{2}$ emissions, which fell by 34\% and 30\%, respectively, between 2008 and 2012. $\mathrm{CO}_{2}$ emissions from gas-fired power plants fell from 273 to $175 \mathrm{MtCO}_{2}$, while emissions from oil-fired power plants fell from 50 to $37 \mathrm{MtCO}_{2}$.

\section{< Insert Figure 1 >}

Additional computational details on the number of installations classified by primary fuel, as well as the average capacity of power generation installations according to primary fuel, can be found in Tables 3 and 4 of the Appendix, respectively.

\subsection{Explained Variable: $\mathrm{CO}_{2}$ emissions of power plants}

The $\mathrm{CO}_{2}$ emissions of power plants constitute the variable of interest in this article.

$$
<\text { Insert Figure } 2>
$$

Figure 2 shows the (indexed) average emissions of power plants in the sample. This variable is pictured as the solid black line in Figure 2. We record a peak in $\mathrm{CO}_{2}$ emissions during the year 2007. This level has subsequently decreased during the years 2008-2009, in line with the economic recession. $\mathrm{CO}_{2}$ emissions in the power sector remain somewhat stable from 2010 onwards.

More specifically, we aim at evaluating the relative contribution of the EU ETS (through carbon pricing) empirically on abatement in the European power sector, alongside other factors outlined in the next section.

\subsection{Explanatory Variables: economic, energy and technical factors}

Broadly, we are looking to explain the variation of $\mathrm{CO}_{2}$ emitted by power plants by four kinds of data:

(i) Economic activity 
The first data selected to represent the economic activity is the EU-27 GDP calculated by Eurostat, measured as chained volumes in base 100 for the reference year 2005. This variable is reproduced in Figure 2, on the same graph as the dependent variable. The rationale behind the inclusion of GDP unfolds as follows. Economic conditions influence the demand for electricity positively by companies and households, pushing fossil-fuel power plants' production and hence $\mathrm{CO}_{2}$ emissions up.

This second period between 2008 and 2012 was affected by the 2009 economic downturn, which was characterized by a worldwide economic contraction that began in late 2007 and took a severe turn to the worse in 2008. Against this backdrop, observers have repeatedly argued that the economic downturn, which is synonymous with a contraction in industrial output, was responsible for the recorded decrease in $\mathrm{CO}_{2}$ emissions in the power sector.

When attempting to measure the emissions of power plants, electricity generation could be an alternative to measure the demand for electricity. Moreover, the utilization capacity of the plants can be considered as well as an explanatory variable in order to consider the specific generation of each. As explained further with this technical data, we can identify two proxies in our database. On the one hand, gross energy production in the country (production_elec) is the variable capturing electricity generation. On the other hand, the technical maximum production capacity of the power plant $(m w)$ is the variable capturing the utilization capacity of the plants. Both variables are tested in the dynamic panel data model using the general-to-specific procedure.

(ii) Energy markets data

\section{< Insert Figure $3>$}

The price of primary energy influences the use of respective power stations through their marginal cost (see Figure 3). To evaluate the impact of production costs in thermal power plants' use, we select coal and gas as the two main fuels used in thermal power plants in Europe. Coal and gas prices are retrieved from Thomson Financial Datastream, using the API 2 CIF ARA Month Ahead contract for coal, and the Zeebrugge spot contract for gas. Annual averages are calculated, and the prices are converted into Euro per MWh. For a study on the interaction and substitution effects between electricity, fuel and carbon prices, see for instance Linden et al. (2013) and Fell et al. (2015).

The $\mathrm{CO}_{2}$ price in Euro/tCO $\mathrm{tC}_{2}$ comes from ICE exchange database. We use the price of the contract for delivery for next December, as it is the most liquid carbon asset traded. The annual average is calculated as the average of all closing prices of the year. The central hypothesis tested regarding the environmental effectiveness of the EU ETS regarding actual abatement is linked to the level of the 
carbon price. Indeed, the $\mathrm{CO}_{2}$ price can, when high enough, incite a switch of production between $\mathrm{CO}_{2}$ intensive power plants to less emitting ones.

The first period was a learning phase: around 1.2 billion allowances were allocated every year, almost entirely free of charge. As this surplus could not be used in phase II, the price of phase I allowances fell to zero. The second period corresponded to the Kyoto Protocol application phase, where the EU ETS $\mathrm{CO}_{2}$ emissions reduction targets for each Member State were in line with those defined in the agreement. Allowances were still mostly allocated free of charge. Unlike in phase I, the option of holding phase II allowances over to phase III enabled the carbon price to remain at a significant level for a time, before gradually falling to below $€ 4.00$ per tonne.

\section{(iii) Technical data of the power plants}

Among technical factors, we retain the primary fuel used by the power plant, the technology of the turbine of the units of the power plant, and the presence of CHP units in the power plant. CHP units have part of their $\mathrm{CO}_{2}$ emissions that can be attributed to heat production and respond to different economic incentives.

Moreover, we take into account power production from low carbon technologies: nuclear and renewable. As they have a lower marginal cost of production than thermal power plants typically, nuclear, hydro and other renewable electricity are the first ones to respond to the electricity demand. They usually come first in the merit order of production.

Last but not least, we control for the production capacity of the power plant. Large thermal power plants will tend to emit more $\mathrm{CO}_{2}$ emissions than smaller units. This factor is analyzed jointly with the energy efficiency of the power plant. For a similar level of production, less energy efficient power plants will emit more $\mathrm{CO}_{2}$. On the other hand, they will tend to be less used than more efficient ones as their use is less profitable.

\section{(iv) Other energy or environmental policies}

Power plants that are submitted to use restriction under the Large Combustion Plant Directive (20,000 hours between 2008 and 2015) are identified on the European Environmental Agency website. The generation capacity of power plants in MW is the sum of the capacity of all production units in the power plant. It comes directly from the database World electric power plant edited by Platts. We take the year of commissioning of the power plant from the same source as a proxy of energy efficiency of the power plant, assuming older plants are less efficient. Cogeneration plants are identified as a 
percentage of MW that comes from CHP units. Primary fuel and type of units are modeled as dummies.

We also take into account low carbon power generation. We take the national data from Eurostat in GWh and separate those between hydro, nuclear and fossil fuel generation. Figure 4 shows the relative importance of various types of non- $\mathrm{CO}_{2}$ emitting forms of generation $v s . \mathrm{CO}_{2}$-emitting generation. For renewable technologies (except Hydroelectricity production), although climatic variations play an essential role in the production level of these technologies, the large increase in recent years is mostly due to the expansion of the production capacity in Europe, mainly wind farms and solar panels. Hydroelectricity production mainly depends on precipitation variations as production is almost not increasing in Europe. Nuclear production depends mainly on the availability of nuclear reactors that can overcome long periods of outage for maintenance.

\section{< Insert Figure $4>$}

Note we neglect to consider meteorological conditions. In case of extreme weather (i.e., colder than usual in winter or hotter than usual in summer), there is an increase in heating or cooling consumption. Hence, meteorological data also influence $\mathrm{CO}_{2}$ emissions through the demand for electricity. Nevertheless, weather variations flatten on a yearly average, the timescale of our data. We do not analyze, either, the magnitude of $\mathrm{CO}_{2}$ emissions off-shoring, as there are limited interconnections with distribution networks of countries outside the EU.

\subsection{Econometric specification and estimation methods}

Recall that this article aims to identify and quantify the most critical determinant of $\mathrm{CO}_{2}$ emissions of the power plants concerned by the EU ETS. To do so, our database allows us to keep track of the verified $\mathrm{C} 02$ emissions of the 1,453 electricity generation plants running on fossil fuels in Europe and its potential drivers from 2005 to 2012, i.e., from the beginning of the EU ETS to the end of its second phase. Thus, thanks to this panel-data sample where cross-sectional units correspond to these 1453 plants we can estimate at the micro-level the relationship between $\mathrm{CO}_{2}$ emissions of the European power sector and their main drivers. Moreover, our panel-data sample is closer to time series data than to cross-sectional data. It thus appears suitable to include in our empirical model the lag dependent variable among the regressors; yielding to a so-called dynamic panel data model.

Section 3.4.1 presents the econometric specification of our model and Section 3.4.2 explains why the generalized method of moments technique (GMM) is the most appropriate econometric method for the 
treatment of dynamic panel models with a relatively large number of cross-sections and small observations over time, as is the case here.

\subsubsection{A dynamic panel data modeling}

We propose the following dynamic panel data model to test for the influence of previously identified $\mathrm{CO}_{2}$ emissions of power plants determinants:

$$
l y_{i, t}=\gamma l y_{i, t-1}+X_{i, t}^{\prime} \beta+\alpha_{i}+\epsilon_{i, t}, \forall i, t
$$

with $t=\{2005, \cdots, 2012\}$ the period on which $\mathrm{CO}_{2}$ emissions data have been obtained, $i$ corresponds to each of the 1,453 electricity generation plants running on fossil fuels in Europe. Thus specified the dependent variable of our model, $l y_{i, t}$, corresponds to the logarithm of the verified $\mathrm{CO}_{2}$ emissions (expressed in ton) of the $i$-th power plant at time $t . X_{i, t}^{\prime}$ is the vector of explanatory variables summarized in Table 5 of the Appendix ${ }^{10}$. There are $K$ regressors in $X_{i, t}^{\prime}$ not including a constant term $\left(X_{i, t}^{\prime}=\left(x_{i, t}^{1}, x_{i, t}^{2}, \ldots, x_{i, t}^{k}, \ldots, x_{i, t}^{K}\right) \forall i, t\right)$ and, as usual, $\left(\alpha_{\mathrm{i}}+\epsilon_{\mathrm{i}, \mathrm{t}}\right)$ correspond to the composite error term. The heterogeneity or individual effect is captured by the constants $\alpha_{i}$ which account for those fixed and inherent factors in each power plant that may be observed or unobserved; all of which are taken to be constant over time $t$. Finally, $\epsilon_{i, t}$ includes effects of a random nature that are not considered in the model. According to Arellano and Bond (1991), Arellano and Bover (1995), and Blundell and Bond (1998), we assume that $\alpha_{i}$ and $\epsilon_{i, t}$ are independently distributed across $i, \epsilon_{i, t}$ is zero mean and $\epsilon_{i, t}$ are independent over $t$ and $i^{11}$.

Because our panel-data sample is closer to time series data than to cross-sectional data; it thus appears suitable to include the lag dependent variable, $l y_{i, t-1}$, among the regressors for studying the determinants of verified $\mathrm{CO}_{2}$ emissions of the power plants concerned by the EU ETS. This lagged term accounts for the short-term dynamic and for the conditional convergence among installations in relation to their verified emissions. A significant $\gamma$ coefficient between 0 and 1 would be indicative of this variable's conditional convergence. The larger the coefficient, the greater the effect of the inertia as an explanatory factor of its own evolution, as well as the slower the convergence speed among the installations. With a double log specification and the remaining factors conditioned, the coefficient $\beta_{k}$ would reflect the short-term elasticity between the verified $\mathrm{CO}_{2}$ emissions of the power plants and the

\footnotetext{
${ }^{10}$ All variables are expressed in natural logs unless otherwise specified.

11 These assumptions would imply moment restrictions that are sufficient to identify and estimate Eq. (1) consistently using a GMM-based approach for $T>3$ (see Arellano and Bond (1991) or Blundell and Bond (1998), among others).
} 
$x_{i, t}^{k}$ variable, while the long run adjustment can be easily deduced by dividing these estimates by $1-$

$\gamma$, i.e $\frac{\beta_{k}}{1-\gamma}$. Hyland and Haller (2018) typically feature such price elasticities between electricity, gas and oil using firm-level data.

\subsubsection{Estimation methods}

The econometric specifications of Eq. (1) is characterized by a dynamic structure that specifies the dependent variable for an individual $\left(l y_{i, t},\right)$ to be partially dependent on its value during previous periods $\left(l y_{i, t-1},\right)$. Thus, conventional panel-data estimation approaches, such as the Fixed Effects or Random Effects estimators, are not appropriate as $l y_{i, t-1}$, is not a strictly exogenous regressor but a weakly exogenous (predetermined) variable. To solve this endogeneity problem and to control for the $\alpha_{i}$ at the same time, one has to first-differencing rather than mean-differencing Eq. (1) to remove the fixed effect. Our generic econometric specification Eq. (1) thus becomes:

$$
\Delta l y_{i, t}=\gamma \Delta l y_{i, t-1}+\Delta X_{i, t}^{\prime} \beta+\Delta \epsilon_{i, t}, \forall i, t
$$

where $\epsilon_{i, t}$ is now assumed to be serially uncorrelated (this assumption is testable, see below). The consistent estimator can then be obtained by Instrumental Variables (IV) estimation of the parameters in the first-difference model (Eq. (2)), using appropriate lags of regressors as the instruments for the transformed variables of the weakly exogenous (predetermined) regressors. This two-step estimation procedure - i) first-differencing rather than mean-differencing Eq. (1) and then ii) applying a kind of $I V$ approach to Eq. (2) - has been proposed by Anderson and Hsiao (1982), Holtz-Eakin et al. (1988), and Arellano and Bond (1991), among others.

Anderson and Hsiao (1982) proposed $I V$ estimation using $\Delta l y_{i, t-2}$ or simply $l y_{i, t-2}-$ which is uncorrelated with $+\Delta \epsilon_{i, t}$ as long as the errors are serially uncorrelated - as a valid instrument for $\Delta l y_{i, t-1}$ in Eq. (2), for all $i$ and $t \geq 3^{12}$. The regressors $X_{i, t}^{\prime}$ are used as instruments for themselves as they are strictly exogenous, otherwise, they can also be instrumented. Although this $2 S L S$ estimator is consistent, it is not asymptotically efficient when the panel has more than three-time series observations. Moreover, its inefficiency might be quite large for a small sample.

Holtz-Eakin et al. (1988) and Arellano and Bond (1991) pointed out these inefficiency problems and propose an alternative, more efficient, GMM-based approach: the GMM-DIF estimator. Using the first

\footnotetext{
${ }^{12}$ If more lags of the dependent variable are included in the model, we have of course to go further back with lags in order to find valid instruments.
} 
difference model (Eq. (2)), the basic idea is to employ the levels of the series lagged two periods or more (i.e. $l y_{i, t-s}$ for $s \geq 2$ ) as instruments in the $G M M$ procedure to overcome the problem of $E\left(\Delta l y_{i, t-1} \Delta \epsilon_{i, t}\right) \neq 0$. Moreover, GMM-based approaches have important advantages over other panel data methods for estimating a dynamic panel data model like (1). First of all, the use of instrumental variables in the GMM procedure allows parameters to be estimated consistently in models with endogenous right-hand-side variables (Arellano and Bond, 1991; Blundell and Bond, 1998). Second, estimates will no longer be biased by omitted variables that are constant over time - installationspecific fixed effects (Holtz-Eakin et al., 1988). Third, the use of instruments potentially allows consistent estimation even in the presence of measurement errors (Bond et al., 2001).

The (one-step) Generalized Method of Moments (GMM) estimator is also called the Arellano-Bond estimator after Arellano and Bond (1991), who detailed the implementation steps for the estimator and proposed tests on the assumption that $\epsilon_{i, t}$ are serially uncorrelated. This estimator can be considered as an extension of the Anderson-Hsiao estimator. The approach adopted by Arellano and Bond (1991) is based on the notion that the estimator proposed by Anderson and Hsiao (1981) does not fully utilize all information available in the sample. Compared to its predecessor, the GMM estimator allows for the most efficient use of information in the dataset by introducing additional lags of the dependent variable as an instrument. In offering these additional instrumental variables, the GMM estimator proposed by Arellano and Bond (1991) leads to more efficient estimates.

It is well-known, however, that the GMM-DIF approach, poses serious bias problems when the series used in the model exhibit significant persistence, as is the case with the variables considered in the model (1). This persistence results in weak instruments, meaning that the correlation between the instrument and the variable to be instrumentalized is small, and the GMM-DIF estimator would be poorly behaved (this problem is also present in 2SLS).

Arellano and Bover (1995) proposed an alternative estimator to solve this weak instrument problem, which is the alternative we use in this paper. Specifically, they propose estimating a system of equations (GMM-SYS) in both first-differences and levels, where the instruments in the level equations are now lagged first differences of the variables. Most of the available instruments for the level equation are mathematically redundant with the instruments used for the difference equations. As a result, only one first difference lag is used for each period and instrumenting variable. For example, $\Delta l y_{i, 2}$ instruments $l y_{i, 3} ; \Delta l y_{i, 3}$ instruments $l y_{i, 4}$ and so on. Using Monte Carlo simulations, Blundell and Bond (1998) and Bond et al. (2001) have shown that instruments for the level equations are still informative even for persistent time series. Because of the good performance of the GMM-SYS relative 
to the GMM-DIF estimator in terms of finite sample bias and efficiency, it has become the most widely used estimator when estimating dynamic panel data models.

The most widely used tests for validating the assumptions involved in the $G M M$ are the $m 1$ and $m 2$ tests, which are first and second-order serial correlation tests of the estimated residuals, respectively, and the Hansen test - corresponding to the alternative test of the Sargan test when using the GMM$S Y S$ estimator - which checks the validity of the instruments used. If the error component $\epsilon_{i, t}$ in Eq. (1) is serially correlated, the GMM estimators will not be consistent due to the fact that some of the instruments will be invalid. If it is not serially correlated, there should be evidence of negative firstorder serial correlation and no evidence of second-order serial correlation in the first differences of the errors $\Delta \epsilon_{i, t}$. Thus, the value of the statistic $m l$ must be negative and its associated $P$-value should be small (less than 0.05 , for example), while the $P$-value associated with the $m 2$ test should be high (greater than 0.05 , for example). The $m 1$ and $m 2$ tests are based on the standardized residual covariance matrix and are asymptotically $N(0,1)$. The null hypothesis of these tests is that $\operatorname{Cov}\left(\Delta \epsilon_{i, t}, \Delta \epsilon_{i, t-s}\right)=0$ for $s=1,2$ is rejected at a level of 0.05 if $P$-value $<0.05$. The Hansen statistic which determines whether the moment conditions selected are valid is used to test the validity of the over-identifying restrictions. The null hypothesis of the Hansen Test is 'instruments used are not correlated with the residuals', meaning over-identifying restrictions are valid. Thus, the associated $P$-value of the value of the statistic of the Hansen Test should be higher than the $10 \%$ level. However, it is well reported that this $P$-value tends to become inflated with an increasing number of instruments. Thus, a P-value close to 1.00 should be interpreted as a clear symptom of the 'too many instruments' problem (Roodman, 2009 a,b), which is an apparent problem of overfitting.

In this article, the relationship between the $\mathrm{CO}_{2}$ emissions of European power plants and their main determinants, as specified in eq(1), is estimated thanks to the GMM-SYS estimator ${ }^{13}$. Diagnostic tests for serial correlation of the residuals, as well as overidentifying restrictions for the validity of the instruments, are passed for all regression results presented in Tables 1 and 2. The next section presents estimates of this estimator.

\section{Results}

We start by presenting the results obtained for the "whole" sample (Section 4.1), which include all types of primary fossil fuels used by power plants included in the database: coal, gas, and oil (and others) power plants. Recall that our database includes variables representing i) technical power plant

\footnotetext{
${ }^{13} \mathrm{We}$ assessed the robustness of our results in the case of two alternative estimators: pooled OLS and FE panel data. Compared to the dynamic panel data GMM-SYS estimator, the results are stable with those two estimators. Results are accessible upon request in order to save space.
} 
characteristics and ii) economic and energy market conditions. As technical data are specific to each type of power plant, it is not possible to include this set of variables in the "whole" sample in order to test and quantify their respective influences. In order to capture the characteristics of each kind of primary fuel and the type of power plant analyzed, one needs to break the "whole" sample into these respective sub-samples.

The subsequent sections present the results for the "whole" and sub-samples named as follows: "Coal" (Section 4.2.1), "Gas" (Section 4.2.2) and "Oil" (Section 4.2.3) power plants sub-samples. So defined, for the year 2005 the "whole" sample includes 1,453 power plants, the "Coal" power plants one contains 352 power plants, the "Gas" one 671 power plants, and the "Oil" one 248 power plants (see Table 4 of the Appendix). Section 4.3 discusses the policy relevance of the findings.

Tables 1 and 2 present the results for the "whole" sample and the "Coal," "Gas," and "Oil" power plants sub-samples respectively. All variables presented in Table 5 of the Appendix have been tested. For each estimate, results are systematically reported after having used the robust variance-covariance matrix estimates (i.e., after using the standard errors adjusted for the $N$ clusters representing the number of installations under consideration).

Unless it is indicated, regression results are presented in the reduced form. These models were chosen by the general-to-specific approach to econometric modeling. As usual, $* * *, * *$ and $*$ respectively indicate 1\%,5\%, and 10\% significance levels and (robust) standard errors of the coefficient estimates are reported into brackets. In each column, the dash "-“ means that the variable under consideration has been first included but finally removed from the reduced form because its coefficient estimate was not statistically significant at the $10 \%$ significance level. Regarding model information, Number of observations and Number of groups indicate, respectively, the number of observations and the corresponding cross-sectional units of the panel-data sample used to perform each regression. In all tables, the number of instruments, the Wald Chi2 ( $P$-value), the $m 1$ and $m 2$ tests but also the Sargan / Hansen test are reported.

We now turn to the comments of the results obtained for each sample and sub-sample. We focus on the signs and significance of the coefficients estimated.

\subsection{All power plants}

Table 1 contains the full sample estimates. Column (1) presents the model for the determinants of $\mathrm{CO}_{2}$ verified emissions in the power plant sector (verified_emissions). The list of candidate explicative variables is detailed in Section 3.3 and Table 5 of the Appendix. 
First, we begin with the comments of Column (1) estimates. The dynamic panel data modeling strategy is accurate since the lagged dependent variable (verified_emissions, $t-1$ ) is statistically significant at the $1 \%$ level. As already explained, this lagged term accounts for the short-term dynamic and the conditional convergence among installations about the verified emissions variable. A significant coefficient between 0 and 1 would be indicative of this variable's conditional convergence. The larger the coefficient, the higher the effect of the inertia as an explanatory factor of its evolution, as well as the slower the convergence speed among the installations.

The economic activity $(G D P)$ is not statistically significant. We explain below in the case of Table 2 why this is the case in the whole sample results: some installations (such as oil) do not respond to GDP, whether other plants (coal and gas) are found to be cyclical with the economic activity.

Coal (coal_price) price is also statistically significant at the $1 \%$ significance level. Its coefficient is negative: any increase in the price of coal would reduce the incentive to produce from the coal power plants, which tends to decrease $\mathrm{CO}_{2}$ verified emissions.

The power plant capacity of production $(\mathrm{mw})$ is statistically significant at the $1 \%$ significance level. Its coefficient estimator is positive. This finding only picks up a size effect, not an energy-intensity one: the more significant the power plant, the more it will emit in terms of $\mathrm{CO}_{2}$ emissions.

The large combustion plant directive (lcpd) percentage is statistically significant at the $1 \%$ significance level. Recall that the LCPD captures the percentage of the production capacity submitted to restricted utilization starting from 2008 under the Large Combustion Plant Directive. It negatively influences the variation of $\mathrm{CO}_{2}$ emission. As anticipated, power plants that have their time of use limited by the LCPD tend to emit less $\mathrm{CO}_{2}$ than others. We verify that several layers of regulation can influence $\mathrm{CO}_{2}$ emissions negatively.

The coal power plants dummy (coal) is statistically significant at the $1 \%$ significance level. Its coefficient estimator is positive, which means that coal power plants are all other things being equal more emitting than gas. Besides, the oil power plant dummy (oil) is statistically significant. Its coefficient is negative, indicating that oil power plants do differentiate themselves from coal and gas plants. All other things being equal, oil power plants are less emitting than coal and gas plants. It is consistent with the fact that oil power plants are generally less used than other power plants as a large part of them are used during peak time, only a few hours per year. 
Lastly, the carbon price (CO2_price) is statistically significant at the $1 \%$ level, but with a counterintuitive positive sign. It seems to indicate that the higher the $\mathrm{CO}_{2}$ price, the higher the $\mathrm{CO}_{2}$ emissions implying that the $\mathrm{CO}_{2}$ market does not provide the right incentives.

Columns (2) and (3) lead us to dig this issue further. Compared to Column (1), they include two additional sets of variables: (i) Dummy_08, (ii) CO2_price_p1 and CO2_price_p2. These different variables have been added to capture more precisely the respective effects of (a) the financial crisis in 2008 and (b) the policy design change which occurred between Phases I and II of the EU ETS.

In Column (2), we have chosen to include only the dummy (Dummy_08) controlling for which period the observations relate to. Dummy_08 is equal to 1 for the observations starting in 2008, and 0 otherwise. This dummy variable is statistically significant at the $5 \%$ level and negative. The variable Dummy_08 captures two sets of information which arise at the same time: Phase II of the EU ETS (January 2008) and the burst of the financial crisis (September 2008). So the negative coefficient of Dummy_08 indicates that $\mathrm{CO}_{2}$ verified emissions have been effectively reduced after 2008. However, one cannot discriminate between the two events only with the Dummy_08 variable as it captures both effects. At first glance, one cannot interpret this result as the proof that the EU ETS has been more environmentally effective in Phase II than in Phase I as the sign of the carbon price (CO2_price) remains positive. We do not comment further this column, as the results are qualitatively similar.

To investigate more in-depth this issue, we introduce in Column (3) - the reduced model - the variables CO2_price_p1, CO2_price_p2, besides Dummy_08,

CO2_price_p1 (CO2_price_p2) is a cross-product of the CO2_price and the dummy EUETS_phase1 (and EUETS_phase2) ${ }^{14}$. Thus, CO2_price_pl corresponds to the price of $\mathrm{CO}_{2}$ during Phase I of the EU ETS, whereas CO2_price_p2 corresponds to the price of $\mathrm{CO}_{2}$ during Phase II of the EU ETS $\left(C O 2 \_p r i c e \_p 1+C O 2 \_p r i c e \_p 2=C O 2 \_p r i c e\right)$. Moving from Column (1) and (2) to Column (3), we replace CO2_price by both $\mathrm{CO} 2 \_p r i c e \_p 1$ and $\mathrm{CO} 2$ price_p2. This strategy allows capturing potential changes in the effect of the $\mathrm{CO}_{2}$ market on verified emissions during Phases I and II.

Except for the variables Dummy_08, CO2_price_p1 and CO2_price_p2, coefficient estimates are remarkably stable when going from Column (1) and (2) to Column (3) as a robustness check. Note, however, that Gas (gas_price) becomes statistically significant at the $1 \%$ significance level similarly

${ }^{14}$ EUETS_phase1 equal to one between 2005-2007 and zero otherwise, EUETS_phase 2 equal to one between 2008-2012 and zero otherwise. 
to Coal (coal_price). The coefficient estimator for the gas price is positive. It remains negative for coal. This finding is consistent with the following interpretation. An increase in the gas price relative to coal results in substituting the use of coal for gas, which leads to an increase in carbon emissions. ${ }^{15}$

Regarding $C O 2 \_p r i c e \_p 1$ and $C O 2 \_p r i c e \_p 2$, both variables are statistically significant at the $1 \%$ level. $C O 2 \_p r i c e \_p 1$ has a negative sign whereas $C O 2 \_p r i c e \_p 2$ has a positive one, suggesting an alternate influence of the $\mathrm{CO}_{2}$ market on verified emissions between Phases I and II. We may cautiously interpret this result as the proof that if the EU ETS has been effectively efficient during Phase I, it has not been the case during Phase II. Previous literature has documented the occurrence of emissions cuts during 2005-07 that may be attributable to the creation of the EU ETS (Ellerman and Buchner, 2007, 2008). We retrieve this result as the negative sign of CO2_price_pl indicates that the carbon price during Phase I did have a negative incentive on verified emissions. In this paper, we complement the body of literature by adding that Phase II has been relatively inefficient regarding emissions reduction, primarily due to the economic decline. The positive coefficient of CO2_price_p2 reflects low allowance pricing.

We demonstrate in our paper that the EU ETS provided the correct economic incentives only during Phase I, with the expected negative sign (i.e., a decrease in $\mathrm{CO}_{2}$ emissions). During Phase II, we assess that the economic recession is the primary driver behind the decrease in $\mathrm{CO}_{2}$ emissions. The $\mathrm{CO}_{2}$ market does not provide the adequate pricing signals. Hence polluters can be left with an allowance price so low that it does not discourage them from polluting, on the contrary.

Having detailed the significant variables in Table 1, we briefly comment on the non-significant variables included in our database. In the whole sample model, variables that were not significant include the geographical location of the power plant, technical data such as cogeneration percentage of the power capacity of the power plant, commission year and, the type of production unit. Regarding the irrelevance of the geographical location of the power plant, from an economic point of view, this result tends to indicate that electricity markets are sufficiently integrated to avoid country-specific distortions. It is not surprising that technical variables are not statistically significant in the whole sample, as they are specific to the kind of primary fossil-fuel used by power plants. For example, some types of turbines are specific to a given fuel: gas turbines or combined-cycle are gas-specific.

\footnotetext{
${ }^{15}$ Although the coefficients are not significantly different from zero, the sign of the coefficient estimator for the $\mathrm{CO}_{2}$ price to switch price ratio is as expected, i.e., negative. An increase in this ratio means an increase in the price of $\mathrm{CO}_{2}$ and/or a fall in the switch price, which encourages a switch to technologies that emit less carbon, and therefore does, in fact, reduce $\mathrm{CO}_{2}$ emissions.
} 


\subsection{Breakdown by coal, gas and oil plants}

Owing to differences between power plants according to their primary fuel, it is not possible to include all variables in the "whole" sample model. To test other technical data, the "whole" sample is thus divided into a coal power plant sub-sample, a gas power plant sub-sample and an oil power plant subsample. Besides, thanks to the fuel data dummy variables (coal, oil, other) in Table 1, we have statistically diagnosed that the "whole" sample results can effectively be further investigated by breaking them up according to the type of fuel. These results are further investigated below in Table 2 .

\section{< Insert Table $2>$}

\subsubsection{Coal power plants sample}

Table 2 (columns (2) and (3)) contains the results for the sub-sample of coal power plants. Columns (2) and (3) present the same reduced model but for the influence of the GDP variable. Notice that in column (2), we tried to capture the effect of the economic activity before and after the financial crisis by introducing GDP_no_crisis and GDP_crisis respectively. Given the substantial changes in the economy that happened during the 2008 subprime crisis, we also have chosen to try to capture whether or not the effect of the economic activity on $\mathrm{CO}_{2}$ emissions has changed before and after the financial crisis. To do so, the GDP variable included in Table 1 is replaced in Table 2 by GDP_no_crisis and GDP_crisis. GDP_no_crisis corresponds to the GDP variable for the period 2005 to 2008. GDP_crisis corresponds to the GDP variable for the period 2009 to 2012.

However, according to the P-Value of the Wald test (54.8\%, bottom of Table 2, secound column), we cannot reject the null hypothesis that both coefficients of GDP_no_crisis and GDP_crisis respectively are equal. Thus, the influence of the economic activity on the verified emissions of coal power plants has not changed dramatically before and after 2008. This leads us to estimate the reduced model only with the GDP variable to capture the influence of the economic activity. These results are presented in Table 2, Column (3).

Compared to the results obtained for the Whole Sample (Table 1, column 3), we only comment on notable differences specific to coal installations. The variables verified_emissions, $t$-1, gas_price, coal_price, $m w$, and lcpd remain statistically significant, and their coefficients remain stable. Variables related to the influence of the $\mathrm{CO}_{2}$ market (Dummy_08,CO2_price_p1, and CO2_price_p2) are not significant, implying that the introduction of the EU ETS did not impact the verified emissions of the coal installations. The baseline production technology is coal, which runs daily for heating and power production. 
Regarding the relative influence of the economic activity, the GDP variable is statistically significant (at $10 \%$ ) and positive for coal plants (.747). It positively influences the variation of $\mathrm{CO}_{2}$ emissions as indicated by its positive sign. This result is in line with our previous assumption: if GDP increases (decreases), $\mathrm{CO}_{2}$ emissions increase (decrease) as well. We assess the sensitivity of $\mathrm{CO}_{2}$ emissions to the slowdown in economic activity within the European Union, as shown in Figure 2 during the year 2008-09.

In the absence of underlying information on the energy efficiency of the power plant, we use as a proxy the commission year of the power plant (commission year). In Table 2, Column (2) and (3), the latter variable becomes statistically significant at the $5 \%$ level. Its estimated coefficient is negative: the younger power plants emit less $\mathrm{CO}_{2}$ than the older ones (as they are less energy-efficient). This result may be interpreted thanks to technological innovation. The European economic environment - mainly driven by environmental policies at the national and regional levels (LCPD, "20-20-20 targets", EU ETS) - provides incentives for coal power producers to use mainly newer installations that are less energy-intensive. The negative effect of the year of commissioning (commission year) illustrates this mechanism: the youngest power plants included in the EU ETS are the least emitting installations.

The influence of the $\mathrm{CO}_{2}$ market on gas and oil installations is detailed afterward.

\subsubsection{Gas power plants sample}

Compared to the Coal sub-sample, the variables related to the influence of the $\mathrm{CO}_{2}$ market (CO2_price_pl and CO2_price_p2) become significant in the Gas sub-sample model (Table 2, column (1)). The introduction of the EU ETS did have an impact on the verified emissions of the Gas power plant, as depicted by the negative sign of the coefficient of CO2_price_pl. The influence of GDP_no_crisis and GDP_crisis becomes positive and statistically significant. The coefficient estimate of GDP_no_crisis (1.14) is lower than that of GDP_crisis (1.27) indicating that verified emissions have been more impacted by the economic activity $(G D P)$ after the burst of the crisis. Therefore, by contrasting the information embedded in the variables Dummy_08,CO2_price_p1 and CO2_price_p2, GDP_no_crisis and GDP_crisis, we infer that the reduction of the $\mathrm{CO}_{2}$ emissions which occurred after 2008 (negative coefficient of Dummy_08), came more from the economic crisis than the effectiveness of the $\mathrm{CO}_{2}$ market. Indeed the coefficient of GDP_no_crisis and GDP_crisis are both positive and stronger for GDP_crisis. On the contrary, if the coefficient of CO2_price_pl is conclusively negative, the one of $\mathrm{CO} 2 \_$price_p2 becomes positive. 
Other coefficients are remaining stable. Hence we do not comment them further except for technical data newly introduced. Dummies for the Combined-Cycled Gas Turbine (CCGT) power plants of first $\left(g t \_c\right)$ and second $(c c)$ generation are both statistically significant at the $1 \%$ level. The interpretation is that these units emit more $\mathrm{CO}_{2}$ than other types of production units. It can be explained because CCGT units are generally used on a semi-base level, longer times than other gas units. Indeed, gas turbines (GT) emit significantly less than steam turbines, whereas small units using internal combustion (IC) do not differ much from a steam turbine.

The rest of the reduced model is almost the same as for other sample and sub-samples. The interested reader can notice the stability of the coefficient estimates as a robustness check.

\subsubsection{Oil power plants sample}

Table 2 (column (4)) contains the results for the sub-sample of oil power plants.

Compared to other sub-samples, the most striking result is the disappearance of the economic activity effect (GDP, but also GDP_no_crisis and GDP_crisis) on the verified emissions of oil installations. We would explain that because the only place where oil power plants are still commissioned is in the islands (Malta, Cyprus), where they serve as baseload generation.

Similar to coal and gas sub-samples, we do not comment upon the other significant variables, as their influence on verified emissions remains intact.

\subsection{Discussion}

In the absence of fiscal agreements around a carbon tax at the international scale, economists have long thought that "Cap and Trade" programs constitute the only feasible way of cutting $\mathrm{CO}_{2}$ emissions collaboratively. Over the last thirty years, the use of transferable permits to control pollution has indeed evolved from little more than an academic curiosity to the centerpiece of the U.S. program to control acid rain ${ }^{16}$ and international programs to control greenhouse gases (Tietenberg, 2010).

Dales (1968) firstly described the virtues of the market mechanism that no person, or agency, has to set the price. The appeals of this environmental regulation tool are twofold: (i) the market equilibrium price of these certificates ensures efficiency in the emission of pollutants, while (ii) firms have an

\footnotetext{
${ }^{16}$ With relatively little fanfare, Title IV of the 1990 Clean Air Act Amendments, the U.S. Acid Rain Program, passed by the U.S. Congress and signed by President George Bush, established the first large-scale, long-term U.S. environmental program to rely on tradable emissions permits (Ellerman et al., 2000).
} 
incentive to invent and adopt pollution-reducing technology. Montgomery (1972) further established the theoretical properties markets in rights (or 'licenses') that exhibit several interesting features: (i) firms which find it more costly to abate pollution will purchase certificates, (ii) and those that find it least costly will abate pollution rather than buy pollution rights.

Taken together, these seminal contributions establish the properties of an emissions trading system, in which rights to emit pollution are available in a fixed and limited aggregate amount and are freely tradable, would induce rational firms to reduce pollution at the least possible cost.

In our paper, we document the intermittent role of the $\mathrm{CO}_{2}$ market in reducing verified emissions. This is mainly due to the economic recession during Phase II, and to a scheme that is overall in exceedance of supply. These arguments have been recently confirmed by other scholars, such as Haites (2018).

On the one hand, the EU ETS has contributed to the emissions reductions, but their share of the overall reduction is not known. For instance, from our merged databases (EUTL and Platts), we glean the information that the $\mathrm{CO}_{2}$ emissions decreased by $186 \mathrm{Mt}$ during 2008-2012, with gas and oil-fired power plants experiencing the sharpest decline (by $34 \%$ and $30 \%$ respectively). Besides, we comment that the more significant effect comes primarily from the contraction of the GDP, at a time when the emissions trading scheme does not offer any additional incentive to cut emissions.

On the other hand, the EU ETS has accumulated a large surplus of allowances and subsequently implemented measures to reduce these surpluses. At the beginning of Phase III (January 2013), the allowance surplus within the EU ETS stood indeed at 2.1 billion allowances. This situation fostered the launch of counter-measures under the form of "backloading" (e.g., withdrawal of allowances) in the short term, and the creation of a Market Stability Reserve (MSR) in the long term.

The EU ETS first phases have indeed accumulated several drawbacks, such as vested interests through lobbying, political capture and bad decisions (an example being the ban on banking between 2007 and 2008, see Alberola and Chevallier, 2009). There are so many constitutive elements of a cap-and-trade emissions trading scheme (e.g., setting the cap and commitment period, spatial and temporal limits, monitoring and reporting, implementing a registry to track allowances, reconciliation and penalties for non-compliance) that its correct functioning might be impeded from infancy.

Modern cap-and-trade schemes now attempt at coping with these imperfections in market design. Several solutions can be proposed to the policymakers. Regarding the initial allocation mechanism, it is possible to increase the share of allowances auctioned and to adopt declining emissions caps.

According to Tisdell (2009), the story behind the failure in the allocation mechanism of the EU ETS was foreseeable. If permits are allocated on historical use, as is quite common, possibly for political reasons, they are likely to provide a windfall economic gain to historical users if the permits can be 
traded. On the contrary, an auctioning of permits would seem more appropriate than historical assignment. Rights to emit pollutants equal to the quantity consistent with the environmental standard could be auctioned or sold at a price which equates the demand for these rights with their supply. Theoretically speaking, the initial allocation mechanism should be neutral at the equilibrium of the permits market.

Besides, it can be proposed to shift from benchmarking "free-for-all" allowances to the distribution of free allowances only to emissions-intensive, trade-exposed (EITE) sources. It has also been advised to reduce the accessibility to foreign offset credits in order to limit oversupplied markets. Regarding the temporal limits, future caps and floor prices can be specified several years into the future.

Our paper also highlights overlapping environmental regulations, under the form of the "20-20-20" targets (including the EU ETS) in addition to the Large Combustion Plant Directive for example. Therefore, we witness that the DG Clima has implemented an emissions trading scheme for regulating greenhouse gases emissions simultaneously with other policies. For policymakers, there is a need to improve the design of the market instrument and its interaction with other legal carbon policies, because the use of multiple instruments produces complex interactive and distributional effects. From an economist's viewpoint, it certainly looks inefficient to supplement market-based policies (such as the EU ETS) by other layers of regulation (such as the LCP Directive). Although, it indeed translates the sustained commitment of the regulator to cut $\mathrm{CO}_{2}$ emissions by all means.

\section{Conclusions}

The aim of the EU ETS, which was set up in 2005, was to reduce $\mathrm{CO}_{2}$ emissions in Europe by setting emission caps for over 11,700 installations which are required to return a volume of allowances that corresponds to their verified $\mathrm{CO}_{2}$ emissions for each annual compliance assessment. This scheme is now in its third phase (2013 - 2020) - significantly different from phases I and II with the introduction of auctioning as an initial allocation mechanism ${ }^{17}$. Phase II of the EU ETS, which lasted from 2008 to 2012, has thus now ended. It corresponded to the Kyoto Protocol application phase, where the EU ETS $\mathrm{CO}_{2}$ emission reduction targets for each Member State were in line with those defined in the agreement. This second period was affected by the 2009 economic downturn, which was characterized by a worldwide economic contraction that began in late 2007 and took a severe turn to the worse in 2008. For the record, we saw an overall $11.9 \%$ fall in emissions between 2008 and $2012(-7.3 \%$

\footnotetext{
${ }^{17}$ Notice it would be difficult econometrically to carry out this research during Phase III, given the shift to auctioning permits. This solution exhibits the advantage of revenue recycling for domestic climate and energyrelated. With backloading, it allows to decrease the emissions cap and allocation by 2030. However, the data from the Spot Market - EU Primary Auction can prove to be difficult to match with the actual spot price series from ICE ECX.
} 
between 2005 and 2012), on a comparable geographical basis, with a steep $11.4 \%$ fall in 2009 compared with 2008 .

Against this backdrop, observers have repeatedly argued that it was not the European carbon market but the economic downturn, synonymous with a contraction in industrial output, which was responsible for the recorded decrease in European $\mathrm{CO}_{2}$ emissions. With ex-post plant-level data on phases I (2005-07) and II (2008-12), this article aims to reach a consensus on the extent to which the EU ETS has been a success so far regarding $\mathrm{CO}_{2}$ emissions abatement. To do so, we propose to identify and quantify the most critical determinant of $\mathrm{CO}_{2}$ emissions of the power plants concerned by the EU ETS.

This paper assesses the contribution of the EU ETS to reduce the level of $\mathrm{CO}_{2}$ emissions using a plant level database. Whereas empirical findings from micro- and macro-econometric approaches can be seen as complementary for scholarly works, we are only interested in the plant-level analysis in this paper. The literature review has revealed a gap indeed from this perspective of full ex-post evaluation of the drivers of $\mathrm{CO}_{2}$ verified emissions for all installations in all countries regulated by the EU ETS (in the case of the power sector).

With this objective, we build a database by merging two databases, namely, the European Union Transaction Log, and the World Electric Power Plants database. Our database allows us to keep track of the verified $\mathrm{CO}_{2}$ emissions of the 1,453 electricity generation plants running on fossil fuels in Europe and its potential drivers from 2005 to 2012, i.e., from the beginning of the EU ETS to the end of its second phase.

Thanks to this (dynamic) panel-data sample, we use the GMM-SYS estimator to estimate at the microlevel the relationship between $\mathrm{CO}_{2}$ emissions of the European power sector and their main drivers. This approach enables us to provide several explanations for the possible causes of the downward trend in the carbon emissions generated by the installations covered by this regulation.

In order to gauge the accuracy of the GMM-SYS estimator, we compared it with two other classes of estimators (pooled OLS and FE panel data) and verified the robustness of our results (accessible upon request to the authors). Besides, we have introduced additional results regarding the validity of our approach (i.e., instrumenting the lagged dependent variable): the Sargan/Hansen test for overidentifying restrictions is safely passed across all regressions, alongside the $\mathrm{ml} / \mathrm{m} 2$ tests for serial correlation of the residuals. 
The main message conveyed by the article is that the EU ETS kept some degree of effectiveness but only during the phases I (2005-07). During phase II (2008-12), its impact has been largely impeded by the deep economic recession in 2008-09 which became the leading cause of the emissions reduction. We also contribute to the energy economics literature by disentangling our analysis not only by periods but also for each type of power plants.

The econometric analysis and the models do not enable us to identify a possible carbon price impact on the coal power plants, which represent more than $60 \%$ of the power sector $\mathrm{CO}_{2}$ emissions. Regarding other power plants (oil and gas), the $\mathrm{CO}_{2}$ price emerging from the EU ETS appears effective in our analysis. The $\mathrm{CO}_{2}$ market has effectively decreased verified $\mathrm{CO}_{2}$ emissions during phase I, whereas it exhibited virtually no effect during phase II. This result suggests an alternate influence of the $\mathrm{CO}_{2}$ market on verified emissions between Phases I and II against the background of the 2008-09 global financial crisis and the 2011 European debt crisis.

On the contrary, our results indicate that verified emissions (of gas power plant) have been more impacted by the economic activity after the burst of the crisis in 2008 than before. Therefore, by contrasting these results, we infer that the reduction of the $\mathrm{CO}_{2}$ emissions which occurred after 2008 came more from the economic crisis than the effectiveness of the $\mathrm{CO}_{2}$ market. We thus complement the body of literature by adding that Phase II of the EU ETS has been relatively inefficient concerning emissions reduction, primarily due to the economic decline. The counterintuitive positive coefficient of the carbon price during Phase II reflects low allowance pricing. The $\mathrm{CO} 2$ market did not provide the adequate pricing signals. Hence polluters can be left with an allowance price so low that it does not discourage them from polluting, on the contrary.

It is important to underline that the economic downturn, which swept away most of the demand for EU allowances, is responsible for the fall in said carbon price and specifically marginalizes its influence regarding the $\mathrm{CO}_{2}$ emission reductions at the installations covered by the European Union. However, this weak price signal is also the result of how the Climate and Energy package has been designed in Europe, with a fixed cap for the EU ETS and fixed renewable energy targets. During the period studied, most of the overlapping emissions reduction comes from renewable policies, but other regulations should not be overlooked as shown by the LCP Directive. Their results regarding $\mathrm{CO}_{2}$ emissions in the power sector risk making the price of $\mathrm{CO}_{2}$ redundant.

Overall, our results suggest, based on the European experience until 2012, that more timely adjustment of policies between each other in the face of changing market conditions has to be considered, which can be relevant in the future design of climate and energy policies not only in Europe but also in other 
parts of the world. Other solutions are part of a global reform of the $\mathrm{CO}_{2}$ market, with the European Central Bank stepping in for instance (Campiglio, 2016).

Last but not least, there is virtually no evidence of shared learning against the background of the early European experience to contribute to the design of other carbon markets in the world. Global trends in emissions trading feature the growth of the number of new ETSs in place, along with the amount of $\mathrm{MTtCO}_{2} \mathrm{e}$ covered (up to 6,780 from the World Bank (2016)'s last counting), and carbon pricing initiatives valued at more than $\$ 50$ billion. From that perspective, the EU has developed cooperation with the Republic of Korea to share technical expertise, as well as lessons learned from the EU ETS's operation over the last decade. In assisting the implementation of the Korean ETS, which is still in its infancy, the EU aims at promoting the cost-effective market-based model of reducing $\mathrm{CO}_{2}$ emissions as discussed in depth by Moon et al. (2019).

Such initiatives should be developed to foster international cooperation around the fight against global warming. The 2018 Nobel Prize in Economic Sciences was famously awarded to Paul Romer ("for integrating technological innovations into long-run macroeconomic analysis"), and for a first time as co-recipient to an academic in the field of climate change in the person of William Nordhaus ("for integrating climate change into long-run macroeconomic analysis"). This recognition appears at times when the Intergovernmental Panel on Climate Change has issued an alarming report (IPCC, 2018): the probability of limiting global warming to $1.5^{\circ} \mathrm{C}$ appears more and more difficult under all stylized pathway of cumulative $\mathrm{CO}_{2}$ emissions.

The UN Secretary-General, Mr. Antonio Guterres, has delivered a similar speech at the 2019 World Economic Forum in Davos: "climate risk is the most important systemic risk for the near future. I believe we are losing the race. (...) in a world in which global challenges are more and more integrated, and the responses are more and more fragmented, and if this is not reversed, it is a recipe for disaster." Effectively cutting $\mathrm{CO}_{2}$ emissions by appropriately designed market instruments appears all the more urgent in the light of these warnings. 


\section{References}

Abrell, J., Ndoye Faye, A., \& Zachmann, G. (2011). Assessing the impact of the EU ETS using firmlevel data. Bruegel Working Paper \#2011/08, Bruegel, Brussels, Belgium.

Alberola, E., \& Chevallier, J. (2009). European carbon prices and banking restrictions: Evidence from Phase I (2005-2007). The Energy Journal 30(3), 51-79.

Anderson, B., \& Di Maria, C. (2011). Abatement and Allocation in the Pilot Phase of the EU ETS. Environmental and Resource Economics 48, 83-103.

Anderson, T.W., Hsiao, C. (1981). Estimation of dynamic models with error components. Journal of the American Statistical Association 7, 598-606.

Anderson, T., Hsiao, C. (1982). Formulation and estimation of dynamic models using panel data. Journal of Econometrics 18, 47-82.

Antimiani, A., Costantini, V., Kuik, O., \& Paglialunga, E. (2016). Mitigation of adverse effects on competitiveness and leakage of unilateral EU climate policy: An assessment of policy instruments. Ecological Economics, 128, 246-259.

Arellano, M. (2003). Panel Data Econometrics. Oxford University Press, Oxford.

Arellano, M., Bond S.R. (1991). Some tests of specification for panel data: Monte Carlo evidence and an application to employment equations. Review of Economic Studies, 58, 277-297

Arellano, M., Bover O. (1995). Another look at the instrumental variable estimation of error component models. Journal of Econometrics, 68, 29-51

Blundell, R., Bond S.R. (1998). Initial conditions of moment restrictions in dynamic panel data models. Journal of Econometrics, 87(1), 115-43

Bond, S.R., Hoeffler, A., Temple, J. (2001). GMM estimation of empirical growth models. Discussion Paper No. 2048, Centre for Economic Policy Research, London. 
Bowsher, C.G. (2002). On testing overidentifying restrictions in dynamic panel data models. Economics Letters 77 (2), 211-220.

Böhringer, C., Koschel, H., \& Moslener, U. (2008). Efficiency losses from overlapping regulation of EU carbon emissions. Journal of Regulatory Economics 33, 299-317.

Bushnell, J. B., Chong, H., \& Mansur, E. T. (2013). Profiting from Regulation: Evidence from the European Carbon Market. American Economic Journal: Economic Policy 5, 78-106

Campiglio, E. (2016). Beyond carbon pricing: The role of banking and monetary policy in financing the transition to a low-carbon economy. Ecological Economics, 121, 220-230.

Convery, F. J., \& Redmond, L. (2007). Market and price developments in the European Union emissions trading scheme. Review of Environmental Economics and Policy 1, 88-111.

Dales, J.H. (1968). Pollution, Property \& Prices: An Essay in Policy-Making and Economics. New Horizons in Environmental Economics (edited by Wallace E. Oates and Henk Folmer), Edward Elgar, London, UK.

De Jonghe, C., Delarue, E., Belmans, R., \& D’haeseleer, W. (2009). Interactions between measures for the support of electricity from renewable energy sources and $\mathrm{CO}_{2}$ mitigation. Energy Policy 37, 47434752.

Delarue, E., Ellerman, A.D. \& D'haeseleer, W.D. (2008), Short-term $\mathrm{CO}_{2}$ abatement in the European power sector, Climate Change Economics 1, 1-21.

Ellerman, A. D., \& Buchner, B. K. (2007). The European Union emissions trading scheme: origins, allocation, and early results. Review of Environmental Economics and Policy 1, 66-87.

Ellerman, D. \& Buchner, B. K. (2008): "Over-Allocation or Abatement? A Preliminary Analysis of the EU ETS Based on the 2005-06 Emissions Data”, Environmental Resource Economics 41, 267-287.

Ellerman, A.D., Joskow, P.L., Schmalensee, R., Bailey, E.M., \& Montero, J.P. (2000). Markets for Clean Air: The U.S. Acid Rain Program. Cambridge University Press, Cambridge, UK. 
Feilhauer, S. M. \& Ellerman, A. D. (2008), A Top-down and Bottom-up look at Emissions Abatement in Germany in response to the EU ETS, CEEPR Working Paper \# 08-017, Centre for Energy and Environmental Policy Research, MIT, Boston, MA, USA.

Fell, H., Hintermann, B., Vollebergh, H. (2015). Carbon content of electricity futures in Phase II of the EU ETS. The Energy Journal 36(4), 61-83.

Eurostat, (2014), European power generation database, Energy Statistics Catalogue, European Environment Agency, Copenhagen, Denmark. Available at: http://epp.eurostat.ec.europa.eu/portal/page/portal/statistics/search database

Fisher, C., \& Peronas, L. (2010), Combining policies for renewable energy: Is the whole less than the sum of its parts? International Review of Environmental and Resource Economics 4, 51-92.

Fischer, C. \& Newell, R. (2004), Environmental and Technology Policies for Climate Change and Renewable Energy, RFF Working Paper \#04-05, Resources for the Future, Washington, DC, USA.

Haites, E. (2018). Carbon taxes and greenhouse gas emissions trading systems: what have we learned? Climate Policy 18(8), 955-966.

Hoel, M. (2012), Second-best Climate Policy, Memorandum \#04/2012, Department of Economics, University of Oslo, Oslo, Norway.

Jaraite, J., and Di Maria, C. (2016) Did the EU ETS Make a Difference? An Empirical Assessment Using Lithuanian Firm-Level Data, The Energy Journal, 37(1), 1-23.

Jaraite, J., \& Kazukauskas, A. (2012). Firm Trading Behaviour and Transaction Costs in the European Union's Emission Trading System: An Empirical Assessment. CERE Working Paper \#2012:9, Center for Environmental and Resource Economics, Umea University, Umea, Sweden.

Holtz-Eakin, D., Newey, W., Rosen, H.S. (1988). Estimating vector autoregressions with panel data. Econometrica 56 (6), 1371-1395.

Hsiao, C. (1986). Analysis of Panel Data. Cambridge University Press, Cambridge.

Hyland, M., \& Haller, S. (2018). Firm-level estimates of fuel substitution: An application to carbon pricing. The Energy Journal 39(6), 1-12. 
Intergovernmental Panel on Climate Change (IPCC). (2018). Global Warming of $1.5^{\circ} \mathrm{C}$ : An IPCC special report on the impacts of global warming of $1.5^{\circ} \mathrm{C}$ above pre-industrial levels and related global greenhouse gas emission pathways, in the context of strengthening the global response to the threat of climate change, sustainable development, and efforts to eradicate poverty. Summary for Policymakers WG-I-II-III. WMO and UNEP, New York, USA.

Jong, T., Couwenberg, O., \& Woerdman, E. (2014). Does EU emissions trading bite? An event study. Energy Policy, 69, 510-519.

Lecuyer O. \& Quirion P. (2013), Can uncertainty justify overlapping policy instruments to mitigate emissions? Ecological Economics 93, 177-191

Linden, M., Makela, M. \& Uusivuori, J. (2013). Fuel input substitution under tradable carbon permits system: Evidence from Finnish energy plants 2005-2008. The Energy Journal 34(2), 1-15.

Martin, R., Muûls, M., de Preux, L. \& Wagner, U. (2014). Industry Compensation under Relocation Risk: A Firm-Level Analysis of the EU Emissions Trading Scheme, American Economic Review, 104, 2482-2508.

Martin, R., Muuls, M., and Wagner, U. J. (2016). The Impact of the European Union Emissions Trading Scheme on Regulated Firms: What Is the Evidence after Ten Years?, Review of Environmental Economics and Policy, 10, 129-148.

Moon, S., Lee, D.J., Kim, T., Kim, K.T. (2019). An Estimation of Market-Based Carbon-Emission Prices Using Comparative Analogy: A Korean Case. The Energy Journal 40, SI "The New Era of Energy Transition," 1-18

Monjon, S., \& Quirion, P. (2011). Addressing leakage in the EU ETS: Border adjustment or outputbased allocation?. Ecological Economics, 70(11), 1957-1971.

Montgomery, W.D. (1972). Markets in licenses and efficient pollution control programs. Journal of Economic Theory 5(3); 395-418.

Petrick, S. and Wagner, U. J. (2014) The impact of carbon trading on industry: Evidence from German manufacturing firms, Kiel Working Papers No. 1912., Germany. 
Platts, (2014), World Electric Power Plants Database, Energy Professional Products, Platts, McGraw Hill Financial, New York, NY, USA. Available at:

http://www.platts.com/Products/worldelectricpowerplantsdatabase

Ringel, M. (2006). Fostering the use of renewable energies in the European Union: the race between feed-in tariffs and green certificates. Renewable Energy 31, 1-17.

Roodman, D. (2009a). A note on the theme of too many instruments. Oxford Bulletin of Economics and Statistics 71 (1), 135-158.

Roodman, D. (2009b). How to do xtabond2: An introduction to difference and system GMM in Stata. Stata Journal 9 (1), 86-136.

Tietenberg, T.H. (2010). Emissions Trading: Principles and Practice, Routledge, $2^{\text {nd }}$ Edition, London, UK.

Tisdell, C.A. (2009). Resource and environmental economics: modern issues and applications. World Scientific, NY, USA.

Wagner, U. J., Muûls, M., Martin, R., \& Colmer, J. (2014). The causal effects of the European Union Emissions Trading Scheme: evidence from French manufacturing plants. In Fifth World Congress of Environmental and Resources Economists, Istanbul, Turkey.

World Bank. (2016). State and Trends of the Carbon Market 2016. The World Bank, Washington, D.C., USA.

Zaklan, A. (2013). Why Do Emitters Trade Carbon Permits? Firm-Level Evidence from the European Emission Trading Scheme. RCAS Working Paper \#2013/19, Robert Schuman Centre for Advanced Studies, Climate Policy Research Unit, European University Institute, Florence, Italy.

Weigt H., Delarue E. \& Ellerman D. (2013), $\mathrm{CO}_{2}$ Abatement from Renewable Energy Injections in the German Electricity Sector: Does a $\mathrm{CO}_{2}$ Price Help? Energy Economics, 40, S149-S158. 
Figure $1-\mathrm{CO}_{2}$ emissions for the EU ETS power and CHP generation by primary fuel used (2005-2012)

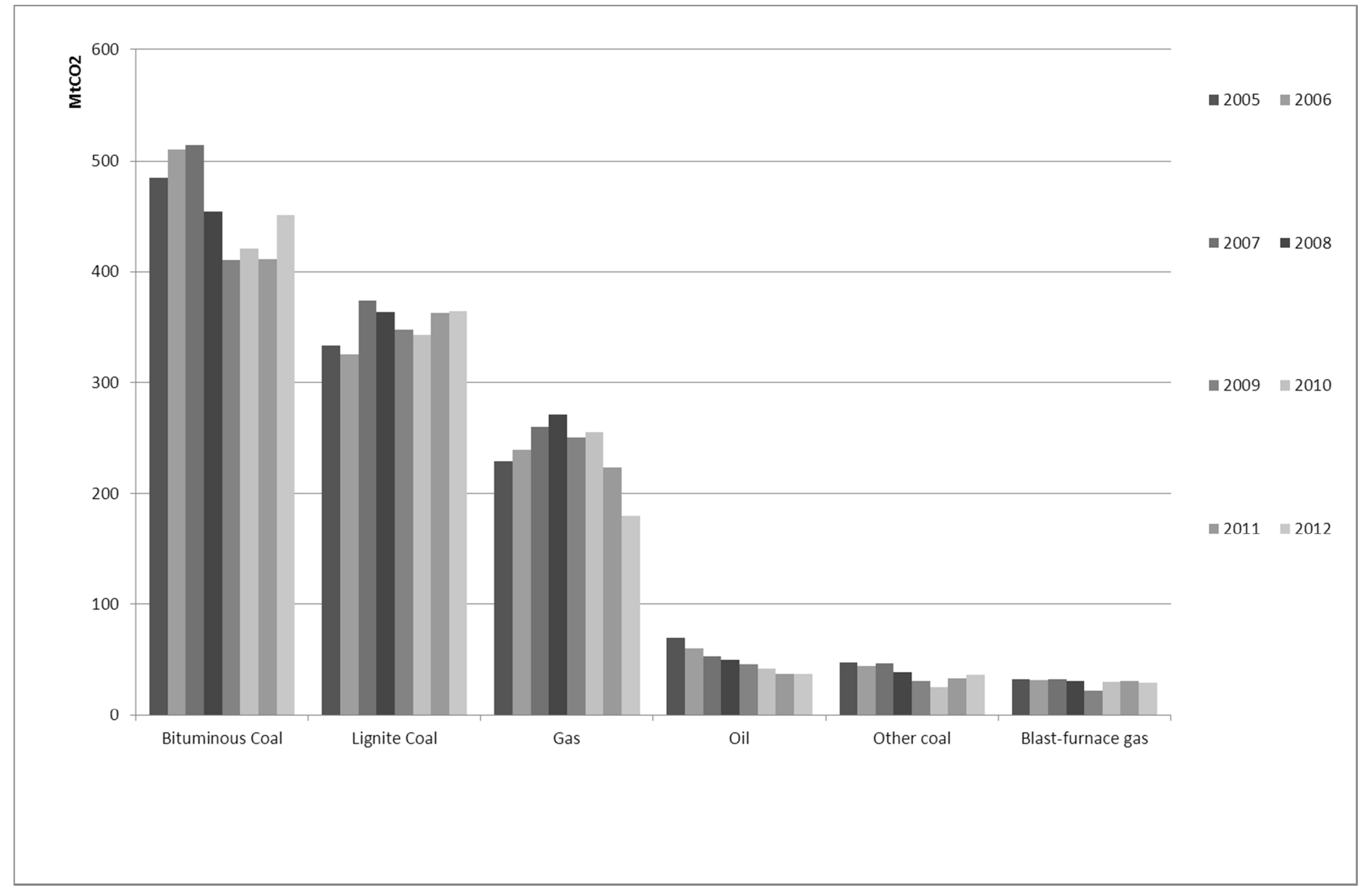

Note: excluding Bulgaria and Romania, as their inclusion in the EU ETS became effective in 2007, the date when they joined the EU.

Source: EUTL and World Electric Power Plant (Platts) 
Figure 2- Power sector $\mathrm{CO}_{2}$ emissions vs. GDP EU-27

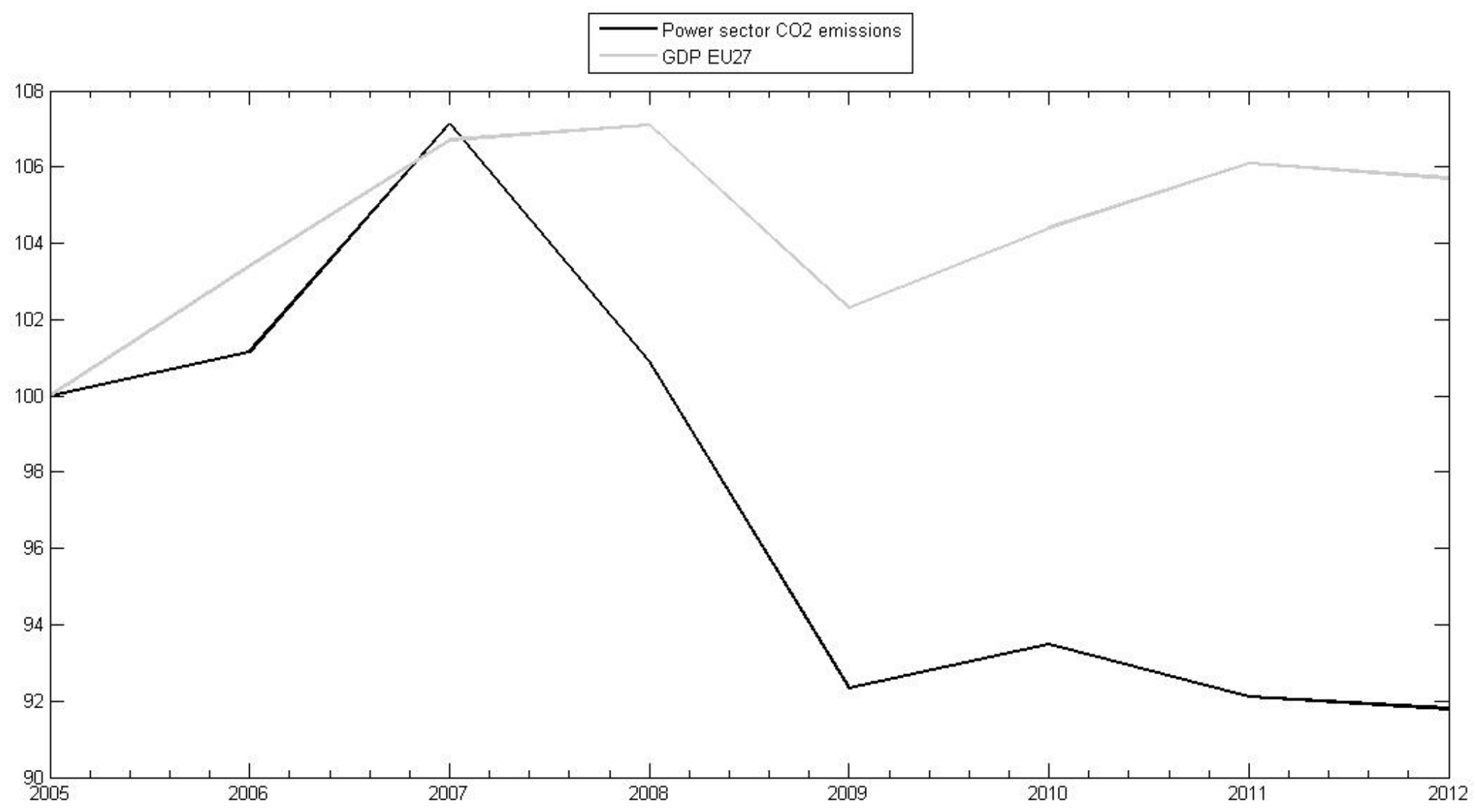

Source: EUTL, WEPP (Platts) and Eurostat 
Figure 3 - Energy and $\mathrm{CO}_{2}$ prices

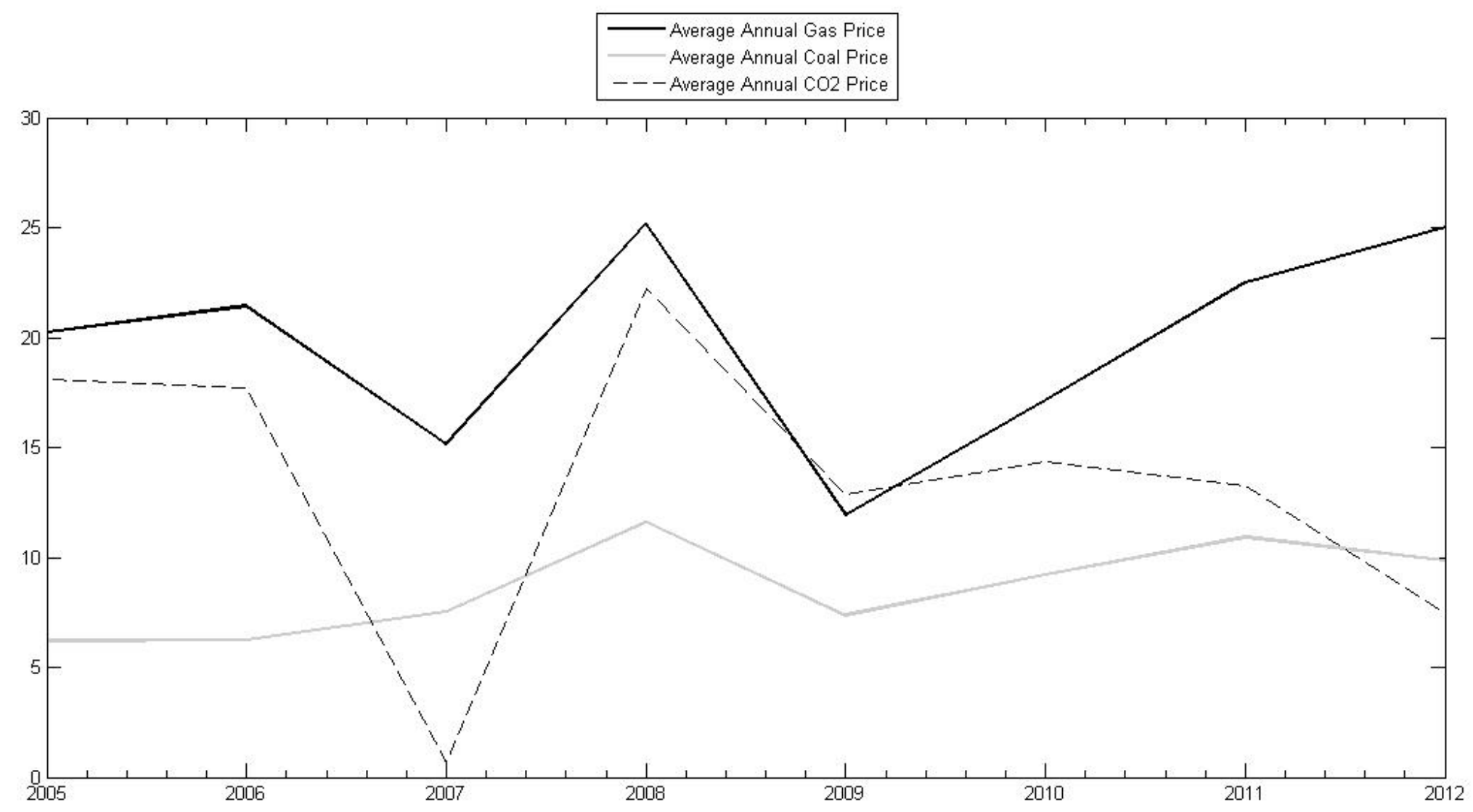

Source : ICE, Reuters 
Figure 4 - Electricity production from non- $\mathrm{CO}_{2}$ emitting sources in Europe vs. Others (fossil-fuel generation)

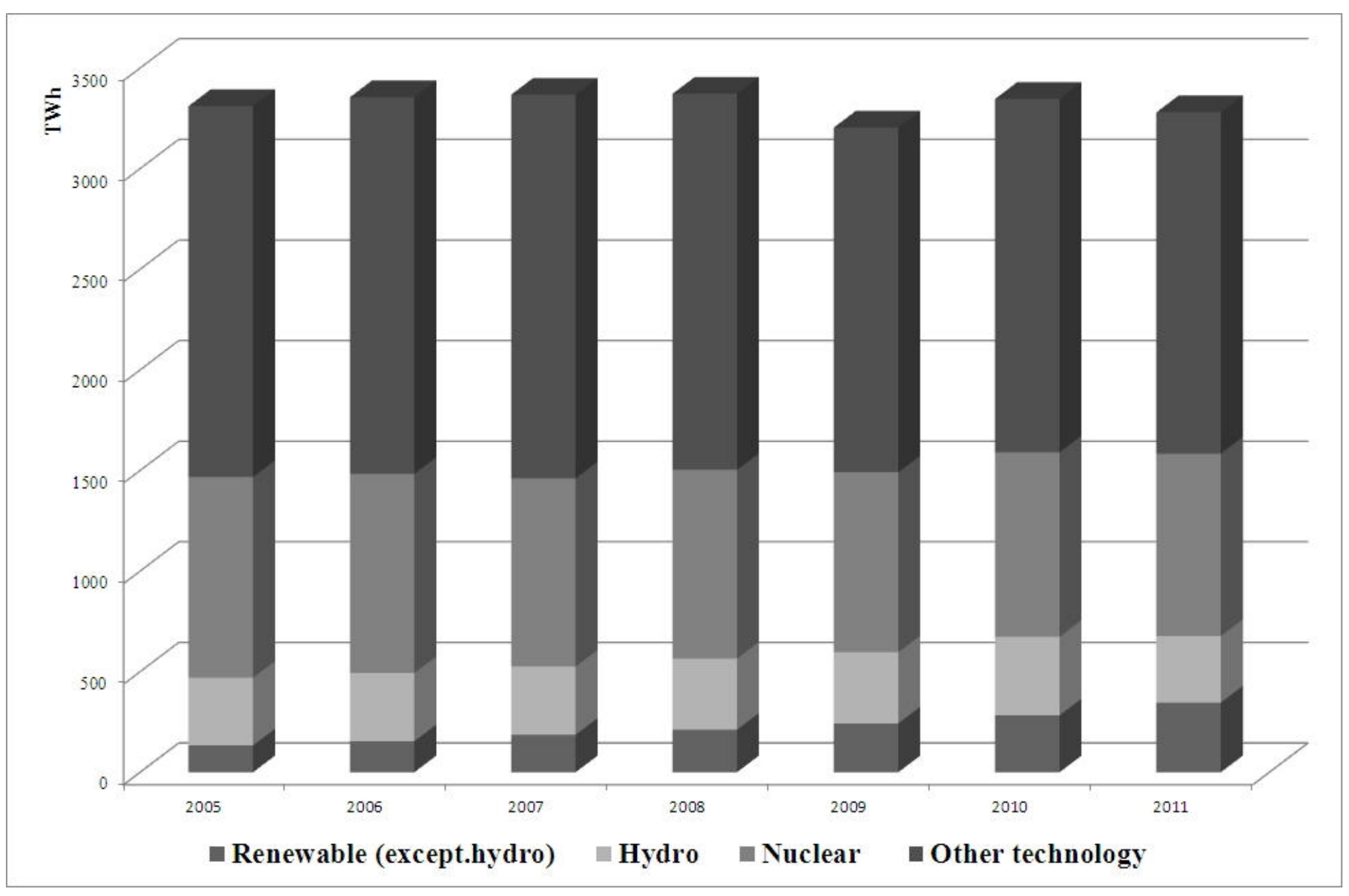

Source: Eurostat 
Table 1 - Regression results for all power plants

\begin{tabular}{|c|c|c|c|}
\hline & $\begin{array}{c}1) \\
\text { Verified emissions }\end{array}$ & $\begin{array}{c}\text { (2) } \\
\text { Verified emissions }\end{array}$ & $\begin{array}{c}(3) \\
\text { Verified emissions } \\
\text { (reduced model) }\end{array}$ \\
\hline \multirow{2}{*}{ verified_emissions, $t-1$} & $.839 * * *$ & $.765^{* * *}$ & $.755^{* * *}$ \\
\hline & $(.034)$ & $(.016)$ & $(.016)$ \\
\hline \multirow[t]{2}{*}{ GDP } & .505 & .478 & - \\
\hline & $(.384)$ & $(.425)$ & \\
\hline \multirow[t]{2}{*}{ gas_price } & -.069 & $-.392^{*}$ & $.826^{* * *}$ \\
\hline & $(.090)$ & $(.238)$ & (.317) \\
\hline \multirow[t]{2}{*}{ coal_price } & $-.301 * * *$ & .352 & $-1.915^{* * *}$ \\
\hline & $(.027)$ & $(.325)$ & $(.638)$ \\
\hline \multirow[t]{2}{*}{ CO2_price } & $.024^{*}$ & $.091^{* *}$ & - \\
\hline & $(.012)$ & $(.044)$ & \\
\hline CO2_price_p1 & - & - & $-.178 * * *$ \\
\hline \multirow{2}{*}{ CO2_price_p2 } & & & $.489^{* * *}$ \\
\hline & - & - & $(.159)$ \\
\hline \multirow[t]{2}{*}{$m w$} & $.150^{* * *}$ & $.217^{* * *}$ & $.225^{* * *}$ \\
\hline & $(.039)$ & $(.026)$ & $(.024)$ \\
\hline \multirow[t]{2}{*}{ Icpd } & $-.309 * * *$ & $-.310 * * *$ & $-.294 * * *$ \\
\hline & $(.060)$ & $(.051)$ & $(.036)$ \\
\hline \multirow[t]{2}{*}{ coal } & $.178^{* * *}$ & $.252^{* * *}$ & $.286^{* * *}$ \\
\hline & $(.044)$ & $(.031)$ & $(.017)$ \\
\hline \multirow[t]{2}{*}{ oil } & $-.304 * * *$ & $-.418 * * *$ & $-.436 * * *$ \\
\hline & $(.070)$ & $(.056)$ & $(.056)$ \\
\hline \multirow[t]{2}{*}{ other } & -.103 & -.155 & -.156 \\
\hline & $(.111)$ & $(.141)$ & $(.145)$ \\
\hline \multirow[t]{2}{*}{ Dummy_08 } & - & $-.333^{* *}$ & $-1.019 * * *$ \\
\hline & & $(.161)$ & $(.348)$ \\
\hline \multirow{2}{*}{ constant } & -.404 & -.091 & $3.398^{* * *}$ \\
\hline & $(1.781)$ & $(1.996)$ & $(.445)$ \\
\hline \multicolumn{4}{|l|}{ Wald Test for } \\
\hline Ico2p1=Ico2p2 (P-value) & - & - & $9.73(0.0018)$ \\
\hline Number of groups & 1395 & 1395 & 1395 \\
\hline Number of observations & 8784 & 8784 & 8784 \\
\hline Number of instruments & 17 & 18 & 18 \\
\hline Wald chi2 (P-value) & $5.63 e+06(0.000)$ & $3.66 \mathrm{e}+06(0.000)$ & $3.31 \mathrm{e}+06(0.0000)$ \\
\hline m1 (P-value) & $-8.27(0.000)$ & $-8.39(0.000)$ & $-8.20(0.000)$ \\
\hline m2 (P-value) & $0.60(0.550)$ & $0.45(0.654)$ & $0.12(0.906)$ \\
\hline Hansen Test $(P$-value $)$ & $4.90(0.556)$ & $5.76(0.451)$ & $5.86(0.439)$ \\
\hline
\end{tabular}

Note: the exhaustive list of variables can be found in the Appendix, Table 5. 
Table 2 - Regression results: breakdown by gas, coal and oil plants

\begin{tabular}{|c|c|c|c|c|}
\hline & $\begin{array}{c}1) \\
\text { GAS } \\
\text { Verified emissions } \\
\text { (reduced model) }\end{array}$ & $\begin{array}{c}\text { (2) } \\
\text { COAL } \\
\text { Verified emissions }\end{array}$ & $\begin{array}{c}\text { (3) } \\
\text { COAL } \\
\text { Verified emissions } \\
\text { (reduced model) }\end{array}$ & $\begin{array}{c}\text { (4) } \\
\text { OIL } \\
\text { Verified emissions } \\
\text { (reduced model) }\end{array}$ \\
\hline verified_emissions, $t-1$ & $\begin{array}{c}.559^{* * *} \\
(.058)\end{array}$ & $\begin{array}{c}.735^{* * *} \\
(.100)\end{array}$ & $\begin{array}{c}.729 * * * \\
(.114)\end{array}$ & $\begin{array}{c}.865^{* * *} \\
(.123)\end{array}$ \\
\hline GDP & - & - & $\begin{array}{l}.747^{*} \\
(.420)\end{array}$ & - \\
\hline GDP_no_crisis & $\begin{array}{c}1.141^{* *} \\
(.451)\end{array}$ & $\begin{array}{l}.695 * * \\
(.326)\end{array}$ & - & - \\
\hline GDP_crisis & $\begin{array}{c}1.268^{* * *} \\
(.460)\end{array}$ & $\begin{array}{l}.700^{* *} \\
(.323)\end{array}$ & - & - \\
\hline gas_price & $\begin{array}{c}2.984^{* * *} \\
(.643)\end{array}$ & $\begin{array}{l}.176 * * * \\
(.064)\end{array}$ & $\begin{array}{l}.176^{*} \\
(.090)\end{array}$ & $\begin{array}{c}1.993^{* * *} \\
(.519)\end{array}$ \\
\hline coal_price & $\begin{array}{c}-5.702 * * * \\
(1.073)\end{array}$ & $\begin{array}{c}-.361^{* * *} \\
(.074)\end{array}$ & $\begin{array}{c}-.382^{* * *} \\
(.144)\end{array}$ & $\begin{array}{c}-4.193^{* * *} \\
(.940)\end{array}$ \\
\hline CO2_price & - & - & - & - \\
\hline CO2_price_p1 & $\begin{array}{c}-.613^{* * *} \\
(.123)\end{array}$ & - & - & $\begin{array}{c}-.441 * * * \\
(.101)\end{array}$ \\
\hline CO2_price_p2 & $\begin{array}{c}1.792^{* * *} \\
(.245)\end{array}$ & - & - & $\begin{array}{c}.663^{* * *} \\
(.191)\end{array}$ \\
\hline$m w$ & $\begin{array}{l}.284^{* * *} \\
(.050)\end{array}$ & $\begin{array}{l}.292^{* * *} \\
(.102)\end{array}$ & $\begin{array}{l}.298^{* *} \\
(.118)\end{array}$ & - \\
\hline Icpd & - & $\begin{array}{c}-.249 * * * \\
(.086)\end{array}$ & $\begin{array}{c}-.242 * * * \\
(.057)\end{array}$ & - \\
\hline commission year & $\begin{array}{c}-.001 * * \\
(.001)\end{array}$ & $\begin{array}{c}-.001^{* *} \\
(.001)\end{array}$ & $\begin{array}{c}-.001 * * \\
(.001)\end{array}$ & - \\
\hline$g t$ & $\begin{array}{l}-.264^{*} \\
(.155)\end{array}$ & & & $\begin{array}{l}-.161 \\
(.479)\end{array}$ \\
\hline ic & $\begin{array}{l}-.207^{*} \\
(.117)\end{array}$ & & & $\begin{array}{c}.034 \\
(.319)\end{array}$ \\
\hline$c c$ & $\begin{array}{c}.394 * * * \\
(.093)\end{array}$ & & & - \\
\hline$g t_{-} c$ & $\begin{array}{l}.274^{* *} \\
(.112)\end{array}$ & & & - \\
\hline Dummy_08 & $\begin{array}{c}-4.363^{* * *} \\
(.568)\end{array}$ & - & - & $\begin{array}{c}-1.077^{* *} \\
(.424)\end{array}$ \\
\hline constant & $\begin{array}{c}1.878 \\
(2.115) \\
\end{array}$ & $\begin{array}{l}-1.025 \\
(1.128) \\
\end{array}$ & $\begin{array}{l}-1.167 \\
(1.551) \\
\end{array}$ & $\begin{array}{l}4.177^{* *} \\
(1.842) \\
\end{array}$ \\
\hline Wald Test for & & & & \\
\hline $\begin{array}{r}\text { Igdpnocrise }=\text { Igdpcrise }(P \text {-value }) \\
\text { Ico2p1=Ico2p2 }(P \text {-value })\end{array}$ & $\begin{array}{l}14.22(0.0002) \\
43.59(0.0000)\end{array}$ & $\begin{array}{c}0.36(0.548) \\
-\end{array}$ & - & $14.97(0.0001)$ \\
\hline $\begin{array}{l}\text { Number of groups } \\
\text { Number of observations }\end{array}$ & $\begin{array}{c}643 \\
4027 \\
\end{array}$ & $\begin{array}{c}342 \\
2251 \\
\end{array}$ & $\begin{array}{c}342 \\
2251 \\
\end{array}$ & $\begin{array}{c}248 \\
1589 \\
\end{array}$ \\
\hline $\begin{array}{l}\text { Number of instruments } \\
\text { Wald chi2 ( } P \text {-value) }\end{array}$ & $\begin{array}{c}31 \\
10179.78(0.000)\end{array}$ & $\begin{array}{c}15 \\
6623.54(0.000)\end{array}$ & $\begin{array}{c}14 \\
13289.86(0.000)\end{array}$ & $\begin{array}{c}15 \\
1715.95(0.000)\end{array}$ \\
\hline $\begin{array}{l}\text { m1 (P-value }) \\
\text { m2 (P-value })\end{array}$ & $\begin{array}{l}-3.74(0.000) \\
-0.88(0.380)\end{array}$ & $\begin{array}{l}-3.65(0.000) \\
-0.06(0.954)\end{array}$ & $\begin{array}{l}-3.45(0,001) \\
-0.07(0.942)\end{array}$ & $\begin{array}{r}-4.71(0.000) \\
1.13(0.260)\end{array}$ \\
\hline Hansen Test ( $P$-value $)$ & $16.74(0.403)$ & $8.73(0.189)$ & $4.92(0.555)$ & $7.51(0.276)$ \\
\hline
\end{tabular}

Note: the exhaustive list of variables can be found in the Appendix, Table 5. 


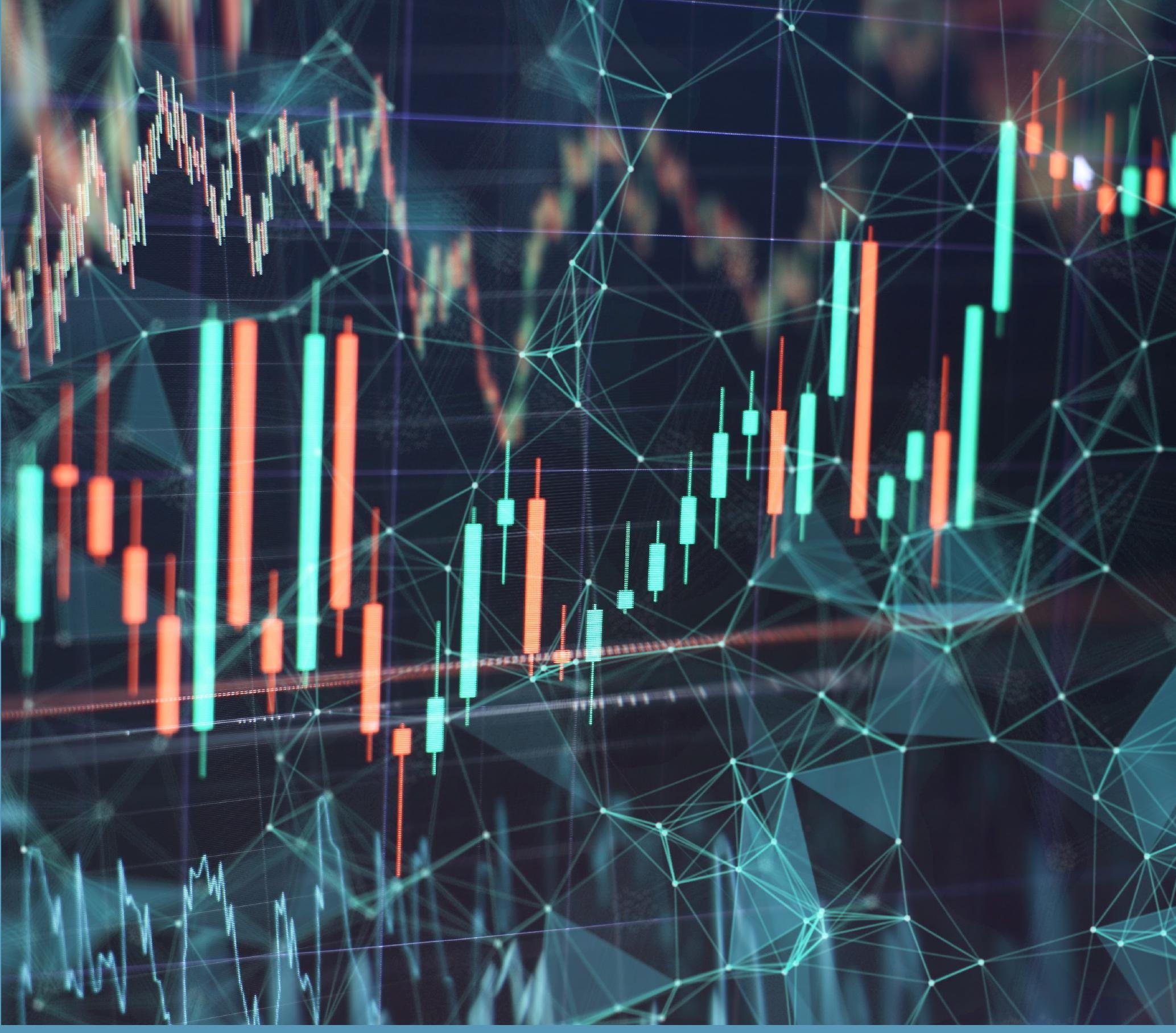

Retrouvez toute la collection

https://www.ifpenergiesnouvelles.fr/article/les-cahiers-leconomie

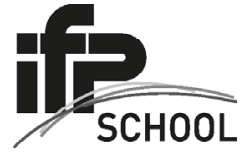

228 - 232 avenue Napoléon Bonaparte

92852 Rueil-Malmaison

www.ifpschool.com

\section{(ifP energers}

1-4 avenue de Bois-Préau

92852 Rueil-Malmaison

www.ifpenergiesnouvelles.fr 